\title{
Comparative study between adsorbents based on magnetic nanoferrite. Application to the removal of methyl orange from wastewater
}

\author{
Sabrine Saad ${ }^{1}$, Sarra Ben Amor ${ }^{1}$, Amel Ben Slimane ${ }^{1 *}$
}

${ }^{1}$ Laboratory for the application of materials to the environment, water and energy - LAM3E (LR21ES15), Faculty of Sciences of Gafsa, University of Gafsa, Tunisia

\section{Corresponding authors:}

Amel Ben Slimane (amelbenslimane71@yahoo.fr); https://orcid.org/0000-0001-8195-6423

\begin{abstract}
Magnetic ferrite (Mg-doped bismuth ferrite) and its clay-based composite (Mg-doped bismuth ferritebentonite) were prepared by self-combustion method utilizing glycine as fuel and served for the removal of methyl orange (MO) from aqueous solutions.
\end{abstract}

The ferrite-based adsorbents were characterized by the measurement of specific surface area (BET), scanning electron microscopy (SEM), Fourier Transform Infrared Spectroscopy (FTIR), X-ray diffraction (XRD). The different experimental parameters that affect the performance of this reaction such as: temperature, contact time, initial dye concentration and mass of adsorbent were investigated. The point of zero charge $\mathrm{pH}$ ( $\mathrm{pH}_{\mathrm{PZC}}$ ) was determined for the two adsorbents. Langmuir and Freundlich adsorption models were employed to provide a description of the equilibrium isotherms. Adsorption tests showed that the equilibrium time is a function of the initial concentration of dye. The adsorption kinetic study indicated that the equilibrium adsorption is established after 300 minutes for $\mathrm{Mg}$-doped bismuth ferrite, while it is established after 180 minutes for Mg-doped bismuth ferrite-bentonite composite. Furthermore, this suggests that the adsorption of $\mathrm{MO}$ on both adsorbents can be perfectly described by pseudo-second order kinetics. The maximum adsorption capacity determined by the mathematical model of Langmuir is equal to $181.8 \mathrm{mg} \cdot \mathrm{g}^{-1}$ for Mg-doped bismuth ferrite and to 188.7 $\mathrm{mg} . \mathrm{g}^{-1}$ for its composite, at $298 \mathrm{~K}$. Adsorption isotherms shows that the Freundlich model perfectly represents adsorption of methyl orange to the prepared Mg-doped bismuth ferrite. The ferrite/bentonite composite has $2-50 \mathrm{~nm}$-sized pores and is indeed a mesoporous material. The small 
pores observed on the surface of the adsorbents are in line with type IV isotherm, with possible capillary condensation of the adsorbate. Moreover, Langmuir model seems to be the most suitable model for the absorption of methyl orange on the $\mathrm{Mg}$-doped bismuth ferrite-bentonite composite. The thermodynamic parameters related to the sorbent/adsorbate system indicate that adsorption is spontaneous and exothermic. The determination of isosteric heat of adsorption suggested that it is indeed a physisorption characterized by weak intermolecular forces between MO and the surface.

Keywords: Magnetic Ferrite; Nanoadsorbent; Methyl orange; Bentonite; Auto-combustion; Adsorption parameters.

\section{Introduction}

Dyes are a crucial part of several industries and their manufacture is ever growing. However, their use in sectors such as, cosmetics, foods, textile, paper industries, agriculture, pharmaceuticals, and medical diagnostics [1], generates considerable amounts of wastewater. The danger of dyes lies in their accumulation generating serious consequences on ecosystems and subsequently on public health [2, 3]. Over the last three decades, several methods of wastewater treatment have been used selectively according to the type of industry and the type of discharge. These include adsorption $[4,5]$ coagulationflocculation [6], biological treatments [7], membrane separation [8], and chemical oxidation [9]. Adsorption techniques have been very effective in treating colored water, removing odors and organic pollutants [10]. Currently, activated carbon is the most widely used adsorbent [11], but the cost of preparation remains very high, which limits its use in developing countries. These issues have encouraged us to research on processing another type of adsorbent such as the magnetic materials [12]. Actually, Nanoadsorbents with magnetic core have emerged as a possible option to traditional adsorbents. They offer a high removal capacity of organic and inorganic pollutants. Particularly, iron oxides have various interesting magnetic, electrical and optical properties. At the nanoscale, these specific properties are improved, which gives them a growing interest in very diverse fields of application. In recent years, different types of ferrite nanoparticles [13, 14] have gained attention due to their reactive surfaces. Other new ferrites were the doped ferrites [15-20]; they are multicomponent materials with enhanced properties of ferrites. It follows that these magnetic particles can be used for many applications such as antibacterial activity [21], photodegradation [22], heavy metal removal [23] and adsorption of various dyes [24]. 
Bentonite is montmorillonite type clay. The elementary sheet of montmorillonite is formed by an octahedral layer between two tetrahedral layers (T-O-T). $\mathrm{Si}^{4+}$ ions are located inside a tetrahedron whose vertices are occupied by oxygen atoms. $\mathrm{Al}^{3+}$ ions are located inside an octahedron whose vertices are occupied by four oxygen atoms and two hydroxyl ions. The elementary sheets are of type 2/1 separated by water molecules and exchangeable cations [25, 26]. Clay minerals such as bentonite have been the subject of numerous studies on their modification in order to impart them new functionalities. Particularly, a few studies reported on the design of magnetic bentonite for the removal of dyes [27-30], however, as far as we are aware no studies reported on the use of bismuth ferritemodified bentonite for dye removal.

For this purpose, we proposed the synthesis of a new doped nano ferrite $\mathrm{BiMgFeO}_{4}$ and its composites ( $\mathrm{BiMgFeO}_{4} /$ Bentonite) for the discoloration of water. A self-combustion derived from the sol gel method using glycine as a fuel [31], was used to remove the anionic dye Methyl Orange (MO), considered as model organic pollutant, from wastewater. These materials were characterized by measuring the specific surface area by BET method, scanning electron microscopy (SEM), Fourier transform infrared (FTIR), X-ray diffraction (XRD). Adsorption of MO was studied in batch system by examining the effect of adsorbent dose, contact time, initial $\mathrm{pH}$, and temperature. Several adsorption isotherm models were used, including Langmuir and Freundlich. Kinetic and thermodynamic studies of adsorption have also been carried out.

\section{Materials and Methods}

\subsection{Chemicals Materials}

All chemicals were purchased from Aldrich: Ferric nitrate nonahydrate $\left(\mathrm{Fe}\left(\mathrm{NO}_{3}\right)_{3} .9 \mathrm{H}_{2} \mathrm{O}\right)$, magnesium nitrate hexahydrate $\mathrm{Mg}\left(\mathrm{NO}_{3}\right)_{2} \cdot 6 \mathrm{H}_{2} \mathrm{O}$, bismuth nitrate pentahydrate $\mathrm{Bi}\left(\mathrm{NO}_{3}\right)_{3} .5 \mathrm{H}_{2} \mathrm{O}$, the Glycine $\mathrm{C}_{2} \mathrm{H}_{5}$ $\mathrm{NO}_{2}$. and hydrochloric acid ( $\mathrm{HCl}, \mathrm{ACS}$ reagent, 37\%) were provided by Sigma-Aldrich, except Methyl Orange $\left(\mathrm{C}_{14} \mathrm{H}_{14} \mathrm{~N}_{3} \mathrm{NaO}_{3} \mathrm{~S}\right.$, supplied by Scharlu) and sodium hydroxide (BioXtra, $\geq 98 \%$ ).

Bentonite used was taken from Jebel Ad-Darin sand from Orbata formation of the region of Sened - Gafsa (Tunisia). Its chemical composition showed maximum silica $\left(\mathrm{SiO}_{2}\right)$ contents on the order of $98 \%$, with the presence of other oxides in small quantities [32]. 


\subsection{Preparation of Bentonite}

In a beaker containing a volume of $1 \mathrm{~L}$ of distilled water, $100 \mathrm{~g}$ of the raw clay (bentonite) was introduced. The mixture was stirred for 24 hours at room temperature. The suspension thus obtained was dried in an oven at $80^{\circ} \mathrm{C}$ until obtaining a constant weight, then crushed with a mortar and finally sifted.

\subsection{Preparation of nanomaterials}

\subsubsection{Preparation of $\mathrm{BiMgFeO}_{4}$}

Mg-doped bismuth ferrite powder was prepared by the self-combustion method [33]. For the preparation of Mg-doped bismuth ferrite powder, an equimolar concentration of bismuth nitrate pentahydrate $\left(\mathrm{Bi}\left(\mathrm{NO}_{3}\right)_{3} .5 \mathrm{H}_{2} \mathrm{O}\right)$, ferric nitrate nonahydrate $\left(\mathrm{Fe}\left(\mathrm{NO}_{3}\right)_{3} .9 \mathrm{H}_{2} \mathrm{O}\right)$ and magnesium nitrate hexahydrate $\left(\mathrm{Mg}\left(\mathrm{NO}_{3}\right)_{2} \cdot 6 \mathrm{H}_{2} \mathrm{O}\right)$ were dissolved independently in $50 \mathrm{ml}$ of distilled water.

First of all, ferric nitrate nonahydrate $\mathrm{Fe}\left(\mathrm{NO}_{3}\right)_{3} \cdot 9 \mathrm{H}_{2} \mathrm{O}$ and magnesium nitrate $\mathrm{Mg}\left(\mathrm{NO}_{3}\right)_{2} \cdot 6 \mathrm{H}_{2} \mathrm{O}$ were mixed under thermal stirring $80-90^{\circ} \mathrm{C}$, until a homogeneous mixture was obtained, then bismuth nitrate pentahydrate $\mathrm{Bi}\left(\mathrm{NO}_{3}\right)_{3} .5 \mathrm{H}_{2} \mathrm{O}$ was added. After a few minutes, the combustible agent (Glycine) was added.

The obtained homogeneous solution was mixed under thermal stirring at $80-150^{\circ} \mathrm{C}$, continuously for 3 hours and evaporated in order to obtain a dry gel, the later was submitted to rapid heating until its self-ignition. The rapid evaluation of a large volume of gas was accompanied by a significant loss of mass during combustion, leading to the formation of numerous foams and sparks, resulting in a bulky and fluffy product in the vessel. The direct transformation to the powder ferrite during combustion was obviously due to the heat generated by the exothermic reaction [34].

The obtained fine powder was grounded with a mortar to obtain nanoparticles. Finally it was kept in an oven for 3 hours at a temperature of $180^{\circ} \mathrm{C}$ to improve its crystallinity and remove residual organic matter.

\subsubsection{Preparation of the $\mathrm{BiMgFeO}_{4} /$ Bentonite composite}

$\mathrm{BiMgFeO}_{4} / \mathrm{Bentonite}$ was synthesized by the auto combustion method: the raw materials used are iron (III) nitrate $\mathrm{Fe}\left(\mathrm{NO}_{3}\right)_{3} .9 \mathrm{H}_{2} \mathrm{O}$, magnesium (II) nitrate $\mathrm{Mg}\left(\mathrm{NO}_{3}\right)_{2} .6 \mathrm{H}_{2} \mathrm{O}$, bismuth (III) nitrate $\mathrm{Bi}\left(\mathrm{NO}_{3}\right)_{3} .5 \mathrm{H}_{2} \mathrm{O}$, bentonite and glycine $\mathrm{C}_{2} \mathrm{H}_{5} \mathrm{NO}_{2}$. The reagents were dissolved in distilled water 
according to a determined stoichiometric ratio, also, the molar ratio between all components was equal to 1 (except glycine).

The synthesis of $\mathrm{BiMgFeO}_{4} /$ Bentonite composite was carried out following the same path way for the preparation of $\mathrm{BiMgFeO}_{4}$ nanoferrite; however, the bentonite was introduced before the addition of the combustible agent.

\subsection{Characterizations of the nanoparticles}

The synthesized samples were submitted to the FTIR analysis which was performed at room temperature over a range between 400 and $4000 \mathrm{~cm}^{-1}$ using $\mathrm{KBr}$ pellets solid (10\% solid) in a Shimadzu 8400-S spectrometer.

Brunauer-Emmet-Teller $\left(\mathrm{S}_{\mathrm{BET}}\right)$ specific surface area and pore structure parameters of synthesized material were obtained from $\mathrm{N}_{2}$ adsorption-desorption measurements at $77 \mathrm{~K}$ using a Micromeritics ASAP 2020 instrument. Prior to measurement, the sample (approximately $40 \mathrm{mg}$ ) was degassed at $300^{\circ} \mathrm{C}$ for 8 hours.

The powder diffractograms were obtained using Powder X-ray diffraction (PXRD) D8 Advance Bruker two-circle diffractometer equipped with a lynxeye detector. The dichromatic copper radiation $\left(\lambda \mathrm{CuK} \alpha_{1} / \alpha_{2}\right)$ was used by the $\theta-2 \theta$ scan in the $2 \theta$ angular range of $5-70^{\circ}$. The wavelengths were: $\lambda_{\mathrm{K} \alpha 1}$ $=0.154060 \mathrm{~nm}$ and $\lambda_{\mathrm{K} \alpha 2}=0.154439 \mathrm{~nm}$. Full diffraction power of $40 \mathrm{~mA} / 40 \mathrm{kV}$ with $0.018^{\circ} \Delta \theta$ step and an exposure time of $2 \mathrm{~s}$ time per step.

The morphology of the samples was evaluated using Scanning electron microscopy (SEM) micrographs obtained on a ZEISS-ULTRA55 SEM microscope.

The $\mathrm{pH}$ of point of zero charge ( $\mathrm{pH}$ PzC) was determined by the $\mathrm{pH}$ drift method [35]. Briefly, many aqueous solutions of $\mathrm{NaCl}(0.1 \mathrm{M})$ with different $\mathrm{pH}$ from 2 to 12 were obtained by addition of hydrochloric acid and sodium hydroxide. Then, $0.15 \mathrm{~g}$ of the nano-ferrite was added to the $\mathrm{NaCl}$ solutions. After 24 hours of stirring, the final $\mathrm{pH}$ was measured. The final $\mathrm{pH}$ was traced as a function of the initial $\mathrm{pH}$. The $\mathrm{pH}$ that intersects with the line $\mathrm{pH}$ (final) $=\mathrm{pH}$ (initial) is known as the $\mathrm{pH}_{\mathrm{PZC}}$ of the nanomaterial. 


\subsection{Batch adsorption}

\subsubsection{Analytical method}

Following the adsorption experiments, the concentration of MO was determined by a Beckman UV/Vis DU 800 Spectrophotometer at a maximum wavelength of $\lambda_{\max }=465 \mathrm{~nm}$. The equilibrium adsorption capacity $\mathrm{Q}\left(\mathrm{mg}\right.$. $\mathrm{g}^{-1}$ ) was calculated according to Eq. (1):

$$
\mathrm{Q}=\frac{\left(\mathrm{C}_{0}-\mathrm{C}_{\mathrm{e}}\right) \mathrm{V}}{\mathrm{m}}
$$

With $\mathrm{C}_{0}$ is the initial concentration of $\mathrm{MO}, \mathrm{C}_{\mathrm{e}}\left(\mathrm{mg} . \mathrm{L}^{-1}\right)$ is the equilibrium concentration of $\mathrm{MO}, \mathrm{V}$ (L) is the volume of the solution, and $\mathrm{m}(\mathrm{g})$ is the mass of the nanoferrite.

\subsubsection{Effect of initial $\mathrm{pH}$, adsorbent dose and temperature}

MO adsorption tests were performed in batch mode to examine the effects of adsorbent dose, initial $\mathrm{pH}$, and temperature. To evaluate the effect of initial $\mathrm{pH}$, experiments were realized at room temperature using $10 \mathrm{~mL}$ of $\mathrm{MO}$ dye solution $\left(50 \mathrm{mg}\right.$. $\left.\mathrm{L}^{-1}\right)$. A fixed dose of adsorbent (10 mg) was added, and the $\mathrm{pH}$ was adjusted from 2 to 12 by adding $\mathrm{HCl}$ or $\mathrm{NaOH}$ solutions $\left(0.1 \mathrm{~mol} \mathrm{~L}^{-1}\right)$ using a $\mathrm{pH}$ meter. The solutions were shaken at temperature-controlled water bath shaker at a speed of $60 \mathrm{rpm}$ for $720 \mathrm{~min}$. The samples were then filtered and the concentration was determined.

In order to determine the most favorable adsorbent dosage, the adsorbent dosage was varied from $5 \mathrm{mg}$ to $150 \mathrm{mg}$. The experiments were performed using the same procedure and conditions described above.

To evaluate the effect of the temperature on the adsorption process of the different adsorbents, we took $100 \mathrm{ml}$ of $\mathrm{MO}$ solution $\left(\mathrm{C}=50 \mathrm{mg}\right.$. $\left.\mathrm{L}^{-1}\right)$ with $50 \mathrm{mg}$ of the considered adsorbent and followed the reaction at different temperatures $\left(2,7,15,25,40,60\right.$ and $\left.75^{\circ} \mathrm{C}\right)$.

\subsubsection{Adsorption kinetic studies}

To assess the effect of contact time on adsorption, the same steps described previously were followed: $50 \mathrm{mg}$ of adsorbent was stirred with $100 \mathrm{~mL}$ of $\mathrm{MO}$ solution $\left(50 \mathrm{mg} . \mathrm{L}^{-1}\right)$ at room temperature and for the desired contact time ranging from 0 to 720 minutes. 


\subsubsection{Adsorption isotherms}

Experiments were performed by varying the initial MO concentration (20-200 $\left.\mathrm{mg} \mathrm{L}^{-1}\right)$, during $720 \mathrm{~min}$. An adsorbent mass of $50 \mathrm{mg}$ is used for each test. The experimental points were examined using Langmuir's Eq. (2) [36], and Freundlich's Eq. (3) [37]:

$$
\begin{aligned}
& \mathrm{Q}_{\mathrm{e}}=\frac{\mathrm{K}_{\mathrm{L}} \mathrm{C}_{\mathrm{e}}}{1+\mathrm{K}_{\mathrm{L}} \mathrm{C}_{\mathrm{e}}} \\
& \mathrm{Q}_{\mathrm{e}}=\mathrm{K}_{\mathrm{F}} \mathrm{C}_{\mathrm{e}}^{\frac{1}{n}}
\end{aligned}
$$

With $\mathrm{K}_{\mathrm{L}}$ : is the Langmuir equilibrium constant associated with the adsorption affinity, Ce: the concentration at the equilibrium; $Q_{e}$ is the adsorbed amount and $C_{e}$ is the equilibrium concentration; $K_{F}$ is the Freundlich constant (heterogeneity factor), and $1 / n$ is the Freundlich coefficient. $n$ is related to sorption affinity and $\mathrm{K}_{\mathrm{F}}$ is related to the sorption capacity.

\section{Results and discussions}

\subsection{General strategy of the work}

Synthesis of ferrite was performed by the self-combustion method. It is characterized by the property of chelating metals by forming a soluble and very stable complex while respecting the volume of the solvent and the following rule:

$$
\mathbf{n}_{\text {glycine }}=\mathbf{n}_{\text {Fe } 3+}+\mathbf{n}_{\mathbf{M g} 2+}+\mathbf{n}_{\text {Bi } 2+}
$$

where $\mathrm{n}$ is the mole number of different materials.

$\mathrm{BiMgFeO}_{4}$ nano ferrite required using the precursor $\mathrm{Fe}\left(\mathrm{NO}_{3}\right)_{3} .9 \mathrm{H}_{2} \mathrm{O}$ salt, and magnesium nitrate $\left[\mathrm{Mg}\left(\mathrm{NO}_{3}\right)_{3} \cdot 6 \mathrm{H}_{2} \mathrm{O}\right]$; they were dissolved in water in a well-defined stoichiometric ratio, under thermal stirring $80-90^{\circ} \mathrm{C}$, until a homogeneous mixture was obtained. Then bismuth nitrate $\mathrm{Bi}\left(\mathrm{NO}_{3}\right)_{3} .5 \mathrm{H}_{2} \mathrm{O}$ was added to the solution. After a few minutes, the combustible agent (glycine) was added. The homogeneous solution was placed under thermal agitation at $80-110^{\circ} \mathrm{C}$ temperature until gelification. The gel was then forced by self-ignition by rapid heating. The rapid assessment of a large volume of 
gas accompanied by a large loss of mass during combustion leads to the formation of a lot of foam and sparks, giving a bulky and fluffy product in the container. The direct formation of ferrite during combustion is obviously due to the heat generated by the exothermic reaction. The fine powder sample obtained was ground with a mortar in order to obtain nanoparticles, and finally it was deposited in an oven for 3 hours at a temperature of $180^{\circ} \mathrm{C}$ in order to improve their crystallinity and eliminate residual organic matter.

The synthesis of $\left(\mathrm{BiMgFeO}_{4} / \mathrm{Bentonite}\right)$ composite was carried out following the same path, but the bentonite was introduced before the addition of the combustible agent.

The general pathway to adsorbent preparation and use is depicted in Figure 1.

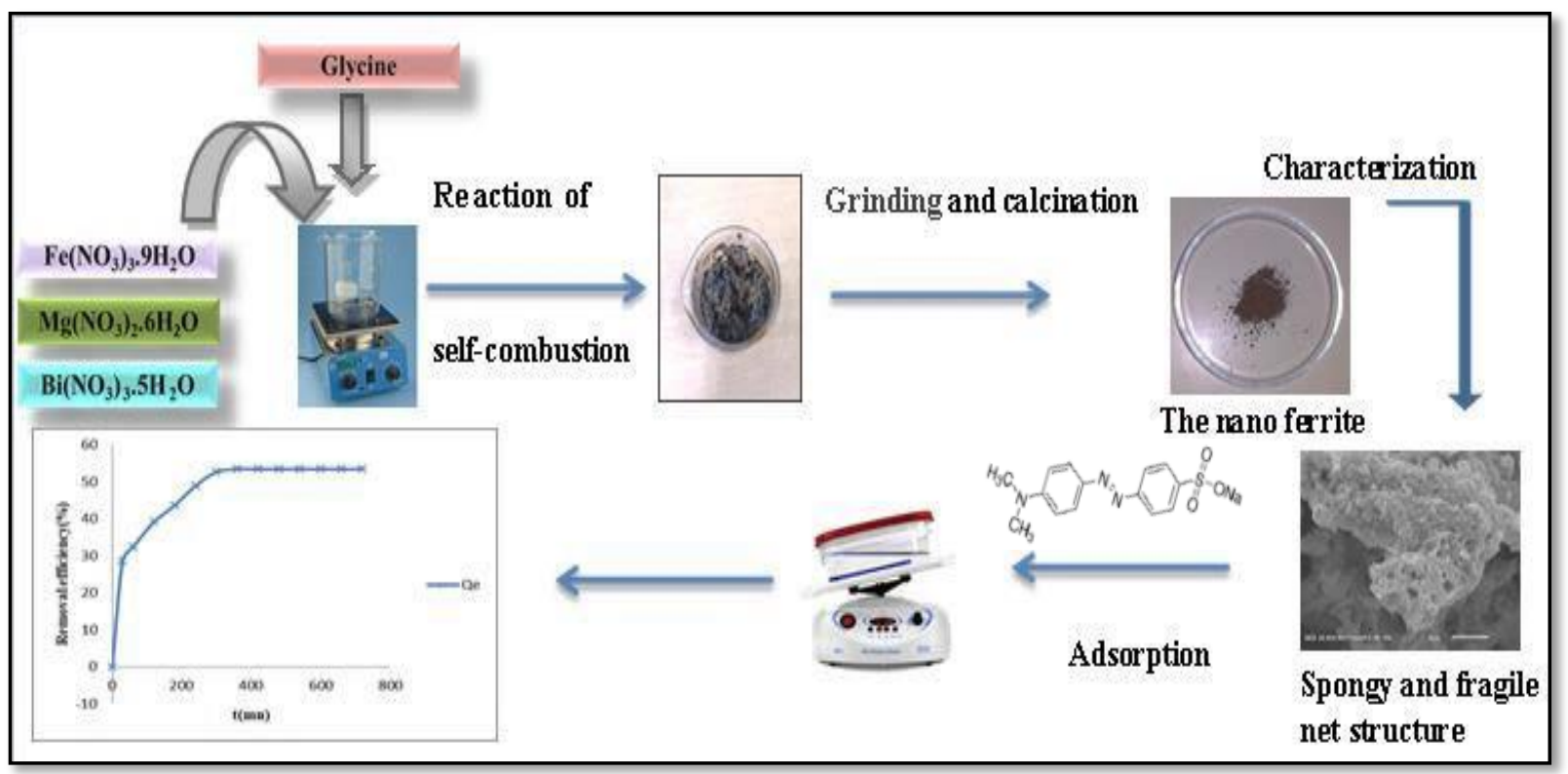

Figure 1. General strategy of preparation of Mg-doped bismuth ferrite Nanoparticles 


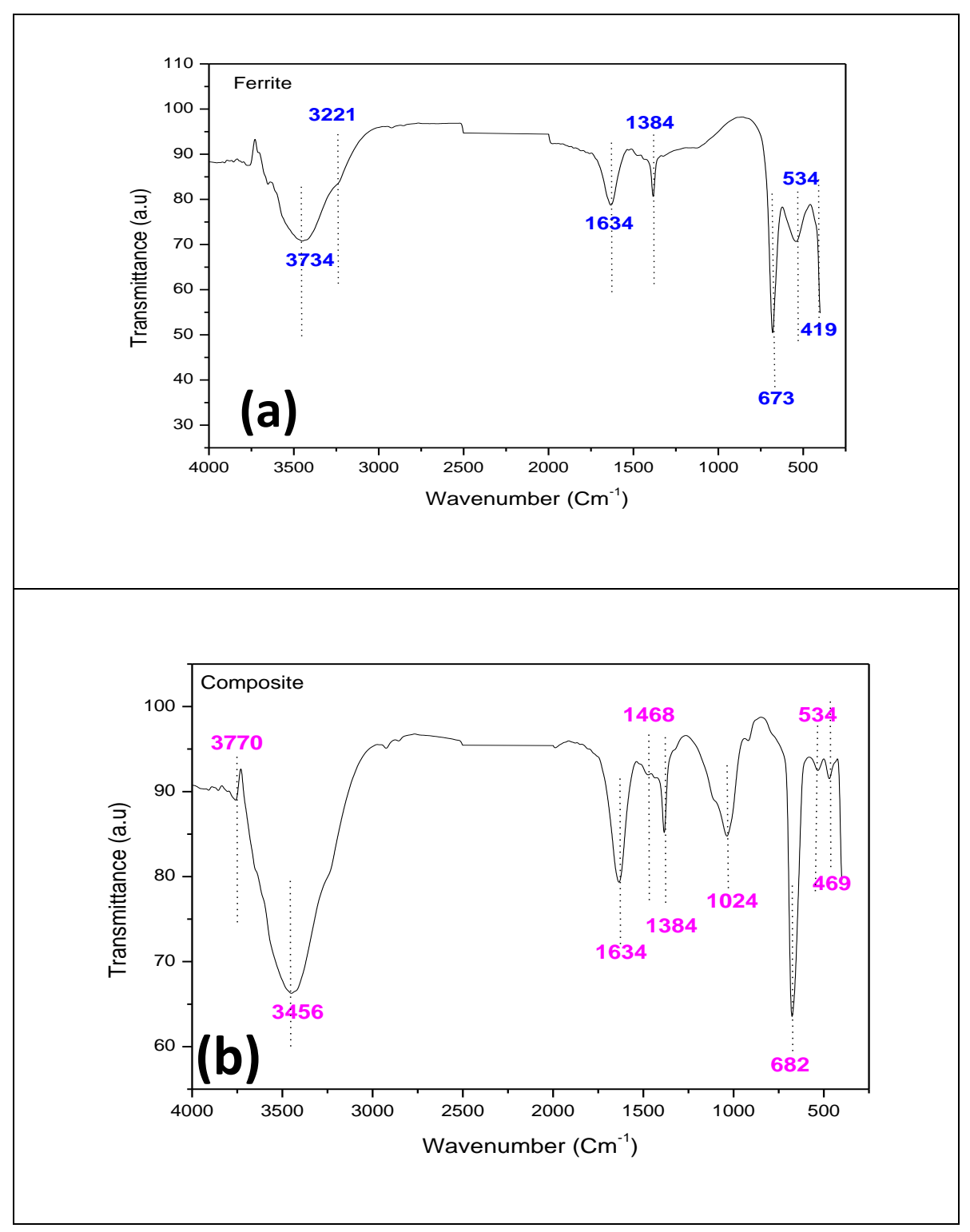

Figure 2. FTIR spectra of (a) $\mathrm{BiMgFeO}_{4}$ ferrite, and (b) $\mathrm{BiMgFeO}_{4} / \mathrm{Bentonite}$ composite.

The analysis of the infrared spectrum of $\mathrm{BiMgFeO}_{4}$ (Figure 2a) shows the existence of a wide absorption band at $3734 \mathrm{~cm}^{-1}$ which corresponds to the elongation vibrations of internal $\mathrm{OH}$ groups. The band located between $1600-1700 \mathrm{~cm}^{-1}$ can be attributed to the valence vibrations of the OH group of the constituent water, in addition to the stretching vibrations of the adsorbed water, and found at 
$1634 \mathrm{~cm}^{-1}$. As well, the peak at $1384 \mathrm{~cm}^{-1}$ corresponds to the vibrations of the nitrate coming from the iron nitrate nonahydrate constituent of the ferrite.

In general, the infrared spectrum of spinel ferrites exhibits two main characteristic bands associated with intrinsic vibrations of the oxygen bonds with metal cations on the two subarrays $[38,39]$.

Indeed, the metal-oxygen bands are located in the range 400-1000 $\mathrm{cm}^{-1}$, the first band being present on the spectrum around $419 \mathrm{~cm}^{-1}$ which corresponds to the Fe-O stretching vibration. The second band is at $534 \mathrm{~cm}^{-1}$ and is due to the elongation of the $\mathrm{Mg}-\mathrm{O}$ bond and the third band at $673 \mathrm{~cm}^{-1}$ which corresponds to the $\mathrm{Bi}-\mathrm{O}$ stretching vibration [40].

The analysis of the infrared spectrum of the $\left(\mathrm{BiMgFeO}_{4} /\right.$ Bentonite) composite (Figure $\left.2 \mathrm{~b}\right)$ allowed to observe the presence of an intense band at $3456 \mathrm{~cm}^{-1}$ relating to an elongation vibration of the $\mathrm{O}-\mathrm{H}$ group derived from the bentonite present in the composite. The little band around 3700 corresponds to the presence of the $\mathrm{BiMgFeO}_{4}$ nanoferrite which corresponds to the elongation vibrations of internal $\mathrm{OH}$ groups. The band at $1634 \mathrm{~cm}^{-1}$ is attributed to the deformation vibrations of the $\mathrm{O}-\mathrm{H}$ bond of the constituent water and to the deformation vibrations of the bonds of the water molecules adsorbed during the preparation of the composite. The band at $1384 \mathrm{~cm}^{-1}$ corresponds to the vibrations of the nitrate. The signal detected around $1468 \mathrm{~cm}^{-1}$ corresponds to sodium carbonate $\mathrm{Na}_{2} \mathrm{CO}_{3}$ derived from the bentonite. We observe as well, a significant signal at $1024 \mathrm{~cm}^{-1}$ which justify the presence of silica due to the stretching vibration of Si-O-Si group of kaolinite or quartz. Moreover, bands of the metaloxygen are located around $400-1000 \mathrm{~cm}^{-1}$ and attributed to the intrinsic stretching vibrations of the metal. The first band is located on the spectrum at $682 \mathrm{~cm}^{-1}$ and corresponds to the stretching vibration of $\mathrm{Bi}-\mathrm{O}$ [41]. The second band is at $469 \mathrm{~cm}^{-1}$ and is due to $\mathrm{Fe}-\mathrm{O}$ bond elongation. Finally, the presence of a band of low intensity around $534 \mathrm{~cm}^{-1}$ corresponds to a stretching vibration of $\mathrm{Mg}-\mathrm{O}$ present in the ferrite.

\subsection{Characterization of the nanoferrites with Scanning electron microscope (SEM) micrographs}

Figure 3 displays SEM images of ferrite (Figure 3a-c) and its composite (Figure 3d-f) at various magnifications. 


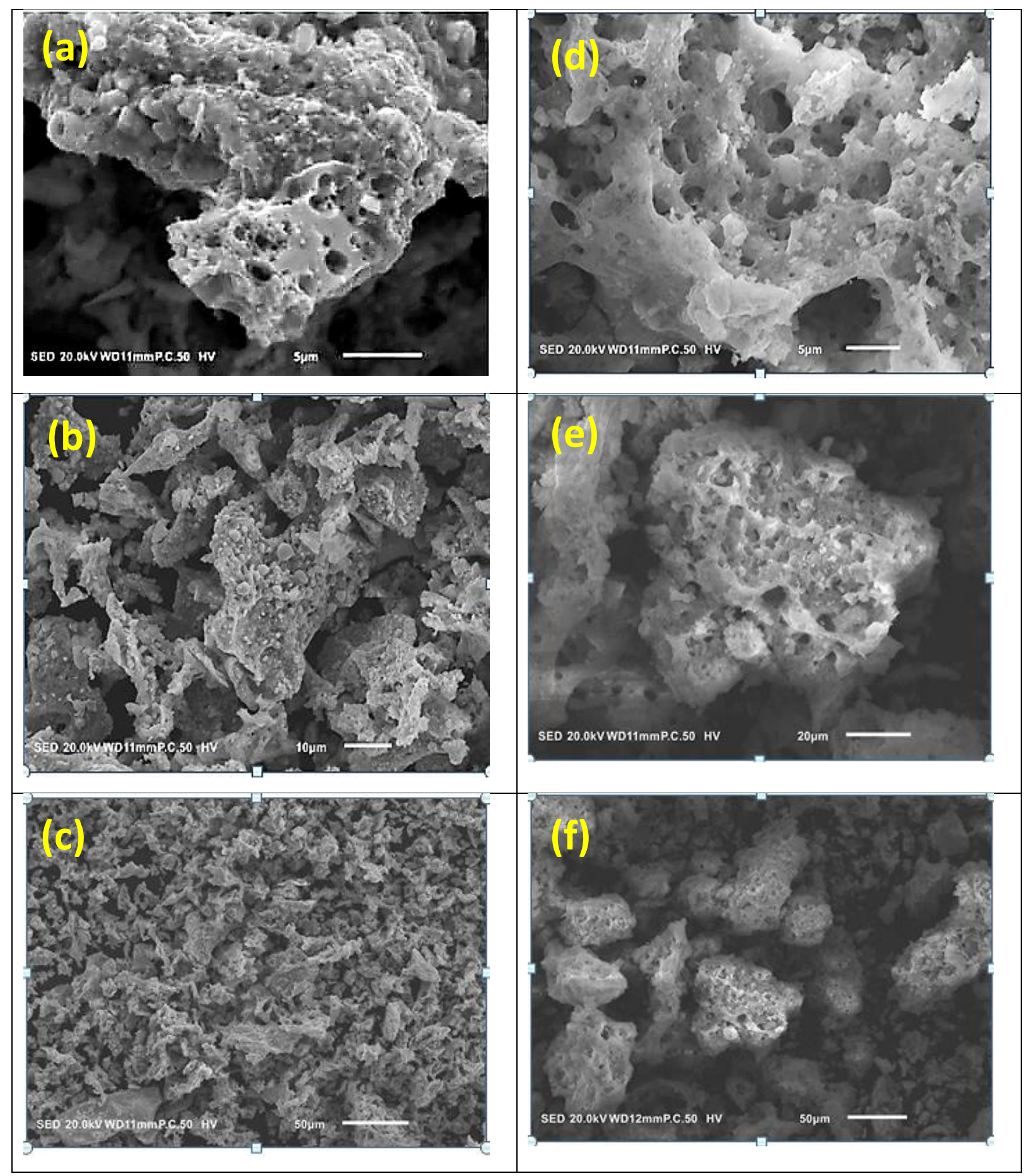

Figure 3. $\mathrm{SEM}$ images of $\mathrm{BiMgFeO}_{4}$ nanoferrite powder (a,b,c), and $\mathrm{BiMgFeO}_{4} / \mathrm{Bentonite}$ composite $(\mathrm{d}, \mathrm{e}, \mathrm{f})$ at different magnifications.

One could observe nodular and non-homogeneous particles of different sizes on the surface of the ferrite (Figure 3b). On the other hand, SEM images show an irregular and very porous structure favorable for good diffusion of dye molecules, with a fairly large percentage of voids, and different 
pore sizes present in the samples. These voids can generally be explained by the release of a large amount of gases ( $\mathrm{NO}, \mathrm{NO}_{2}, \mathrm{CO}, \mathrm{NH}_{3}$ and $\mathrm{H}_{2} \mathrm{O}$ ) during the combustion process [42, 43] (Figure 3a). Indeed, the release of associated gas results in a highly porous structure [44]. Microcavities observed on the surface of the adsorbent, seem to indicate a very irregular structure porous favorable for good diffusion of dye molecules.

The $\mathrm{BiMgFeO}_{4} /$ Bentonite exhibits important spongy structure (Figure 3d-f), which is due specifically to the effect of the combustion agent used (glycine). The pores of different sizes observed in the samples are related to the voids which correspond to the release of a large quantity of gases during the combustion reaction. Since the release of associated gas results in a highly porous structure with nonhomogeneous and agglomerated particles. This resulting porosity presents a very important factor for the evolution of adsorption.

The incorporation of bentonite during the preparation of the ferrite-derived composite has helped to modify the morphological structure of the latter's surface, as well as the number and size of cavities and pores in the nanocomposite. This implies that the composite thus prepared, would be more subject to the adsorption of the molecules of the dye. By comparing the images of the surface morphology of mineral substrates $\left(\mathrm{BiMgFeO}_{4}\right)$ nanoferrite and its $\mathrm{BiMgFeO}_{4} /$ Bentonite composite, at the same magnification (once with a scale of $5 \mu \mathrm{m}$, and again with a scale of $50 \mu \mathrm{m}$ ), one could note the enrichment of the surface of the prepared composite by larger porous cavities and the increase in the spongy structure of the adsorbent, as well as its heterogeneous character. This phenomenon enhances the dye adsorbing capacity of the composite.

\subsection{Characterization of nanoferrites with X-ray diffraction (XRD)}

Figure 4 describes the diffractogram study obtained from the XRD analysis of ferrite nano powder and its composite. Figure 4a shows X-ray diffraction patterns of $\mathrm{BiMgFeO}_{4}$ nanoferrite particles at room temperature. The data were collected at $2 \theta$ range from 20 to 70 degree. The diffraction peaks for $\mathrm{BiMgFeO}_{4}$ nanoparticles exist at $2 \theta$ values of $27.18^{\circ}, 27.84^{\circ}, 32.72^{\circ}, 46.45^{\circ}$, and $55.54^{\circ}$. They are very close to the position of the diffraction peaks corresponding to the $\mathrm{BiFeO}_{3}$ international standard diffraction data (card JCPDS no.01-073-0548) and to the standard XRD pattern for $\mathrm{MgFe}_{2} \mathrm{O}_{4}$ (card JCPDS number 89-3084). The same diffraction peaks exist in the XRD spectra (Figure 4b) which prove that the prepared ( $\mathrm{BiMgFeO} 4 / \mathrm{Bentonite})$ composite contains the nanoferrite and a mixture of 
several minerals, such as kaolinite $\left(\mathrm{Al}_{2} \mathrm{Si}_{2} \mathrm{O}_{5}(\mathrm{OH})_{4}\right)$ (which corresponds to the $2 \theta=12.37^{\circ}$ and to $2 \theta$ $\left.=24.92^{\circ}\right)$. The peaks appearing towards $\left(2 \theta=12.31^{\circ}\right),\left(2 \theta=26.59^{\circ}\right)$ and $\left(2 \theta=29.34^{\circ}\right)$ corresponds to the calcite $\mathrm{Ca}\left(\mathrm{CO}_{3}\right)$ and mainly the quartz $\left(\mathrm{SiO}_{2}\right)$ present in big proportion in the bentonite used for the preparation of composite.

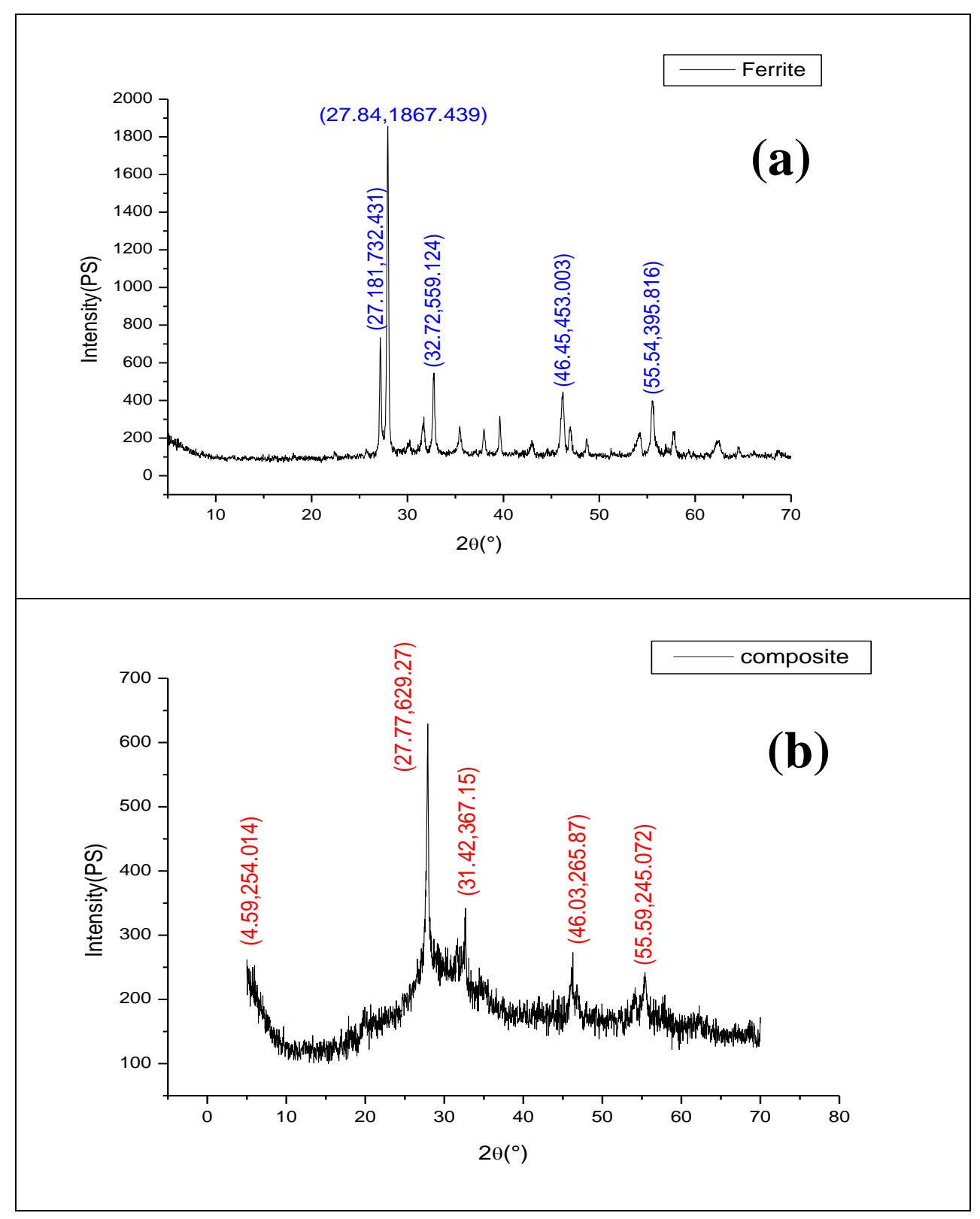

Figure 4. XRD patterns of $\mathrm{BiMgFeO}_{4}$ nanoferrite (a), and $\mathrm{BiMgFeO}_{4} /$ Bentonite composite (b). 


\subsection{Measurement of the specific surface area of the composites by BET analysis.}

The specific surface area and the distribution and pore size were determined from adsorptiondesorption isotherms of liquid nitrogen at $-195^{\circ} \mathrm{C}(77 \mathrm{~K})$ [45]. Because of the limitation in $\mathrm{N}_{2}$ adsorption, only the external surface of the material is able to be measured by this method [46]. Below the results for the composite (Figure 5).

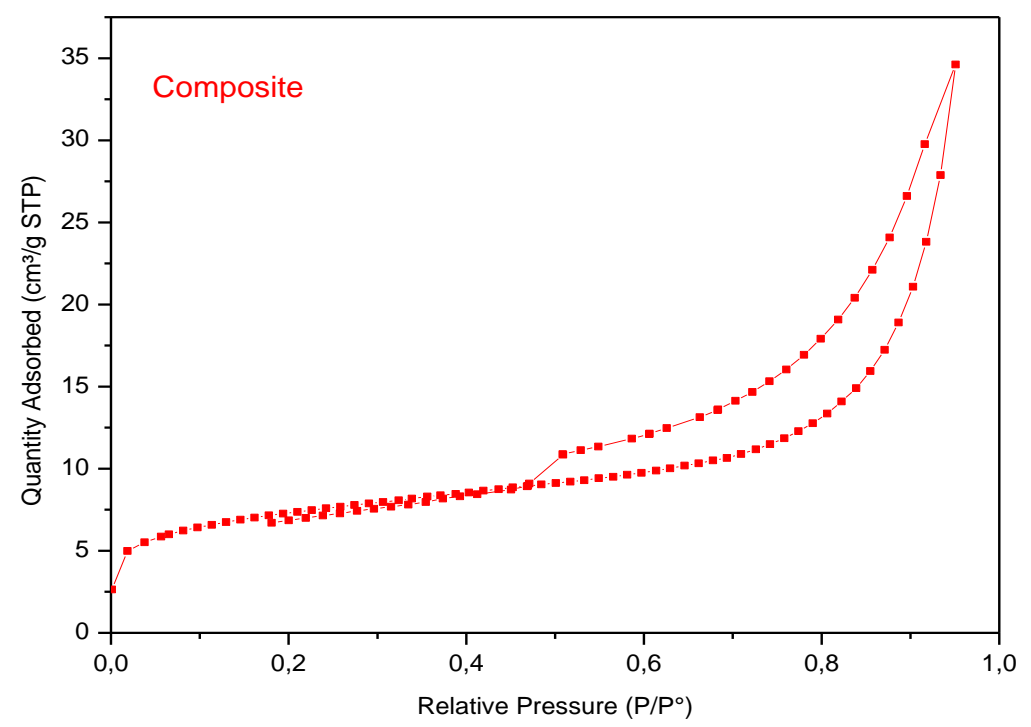

Figure 5. Adsorption and desorption isotherms of $\mathrm{N}_{2}$ on $\mathrm{BiMgFeO}_{4} /$ Bentonite composite.

Figure 5 suggests that the isotherm plot recorded with $\mathrm{BiMgFeO}_{4} /$ Bentonite composite belongs to the type IV adsorption isotherm in the classification of Brunauer, Deming, Deming and Teller (BDDT). The analysis of adsorption and desorption isotherms of dinitrogen at low temperature of the materials shows at low pressures a notable adsorption followed by a gradual increase in the amount of quantity of adsorbed gas, which is quite prominent for the composite compared to that of ferrite. Then, at a relatively high pressure, a distinguished capillary condensation phenomenon is observed during desorption by the presence of an H3-type hysteresis loop large enough for the composite.

The volume of $\mathrm{N}_{2}$ adsorbed by $\mathrm{BiMgFeO}_{4} /$ Bentonite composite is quite high, and reached $34 \mathrm{~cm}^{3} / \mathrm{g}$ at high pressure, due to the increase of the specific surface. The specific surface area calculated using the BET equation is $\sim 25.0 \mathrm{~m}^{2} / \mathrm{g}$ for the composite. The size of the nanoparticles is $15.463 \mathrm{~nm}$ for the pore diameter of $\left(\mathrm{BiMgFeO}_{4} /\right.$ Bentonite) composite and the size of the pore volume is $0.0456 \mathrm{~cm}^{3} / \mathrm{g}$ (Table 1). The mean volumes of the pores as well as their diameters of the powder were calculated by 
the method of Barrett - Joyner - Halenda BJT [47]. The composite containing pores with diameters between 2 and $50 \mathrm{~nm}$, is indeed a mesoporous material with a pore diameter equal to $15.4631 \mathrm{~nm}$ and a surface area of $24.957 \mathrm{~m}^{2} / \mathrm{g}$. This mesoporous structure is favorable for use in the elimination of the MO anionic dye. The pores observed on the surface of the adsorbents showing small diameters, confirm that it is indeed a type IV isotherm.

Table 1: Textural and morphological of the $\mathrm{BiMgFeO}_{4} /$ Bentonite.

\begin{tabular}{|c|c|c|c|}
\hline Adsorbent & Pore volume $\left(\mathbf{c m}^{3} / \mathbf{g}\right)$ & Pore diameter $(\mathbf{n m})$ & $\begin{array}{c}\text { Specific surface } \\
\text { area SBET }\left(\mathbf{m}^{2} / \mathbf{g}\right)\end{array}$ \\
\hline Composite & 0.0456 & 15.463 & 25.0 \\
\hline
\end{tabular}

\subsection{Determination of point of zero charge pH (PZC) for the nanoferrites}

The surface of the adsorbent and its nature has a remarkable influence on the adsorption of any types of ions at different $\mathrm{pH}$. The surface charge of the adsorbent can be characterized by the $\mathrm{pH}$ pzc. Below this value when $\mathrm{pH}<\mathrm{pHpzc}$ there is an excess of positive charge on the surface, so that anions can be adsorbed. Conversely, beyond this value at $\mathrm{pH}>\mathrm{pHpzc}$, the surface charge would be negative so that the cations can be adsorbed. [48].

The $\mathrm{pH}_{\mathrm{PZC}}$ of the nano ferrite is deduced from the intersection of the experimental curve of final $\mathrm{pH}$ versus initial $\mathrm{pH}$ with that of the bisector (final $\mathrm{pH}=$ initial $\mathrm{pH}$ ) [49].

As shown in Figure 6a, for $\mathrm{BiMgFeO}_{4}$ the $\mathrm{pH}_{\mathrm{PZC}}$ (nanoferrite) is 7.7. If the $\mathrm{pH}$ of the solution is lower than 7.7 the surface of the adsorbent is charged positively and anions can be adsorbed at this $\mathrm{pH}$ zone. The surface functional groups of the adsorbent will be protonated by excess $\mathrm{H}^{+}$protons from the solution, the support is attractor of negatively charged adsorbate.

According to the curve (Figure $6 \mathrm{~b})$, the $\mathrm{pH}_{\mathrm{PzC}}\left(\mathrm{BiMgFeO}_{4} / \mathrm{Bentonite}\right)=8.2$. This indicates that when solution $\mathrm{pH}$ is below 8.2 , the surface of $\left(\mathrm{BiMgFeO}_{4} /\right.$ Bentonite $)$ composite is positively charged via the protonation of hydroxyl group bound to metal

$\left(\mathrm{M}-\mathrm{OH}+\mathrm{H}^{+} \rightleftarrows \mathrm{M}-\mathrm{OH}_{2}^{+}\right.$, where $\mathrm{M}$ is metal).

whereas the surface of the composite is negative at solution $\mathrm{pH}$ above $\mathrm{pH}_{\mathrm{PZC}}$ due to the deprotonation of hydroxyl group bound to metal. 
$\left(\mathrm{M}-\mathrm{OH}+\mathrm{OH}^{-} \rightleftarrows \mathrm{M}^{-} \mathrm{O}^{-}+\mathrm{H}_{2} \mathrm{O}\right)$.

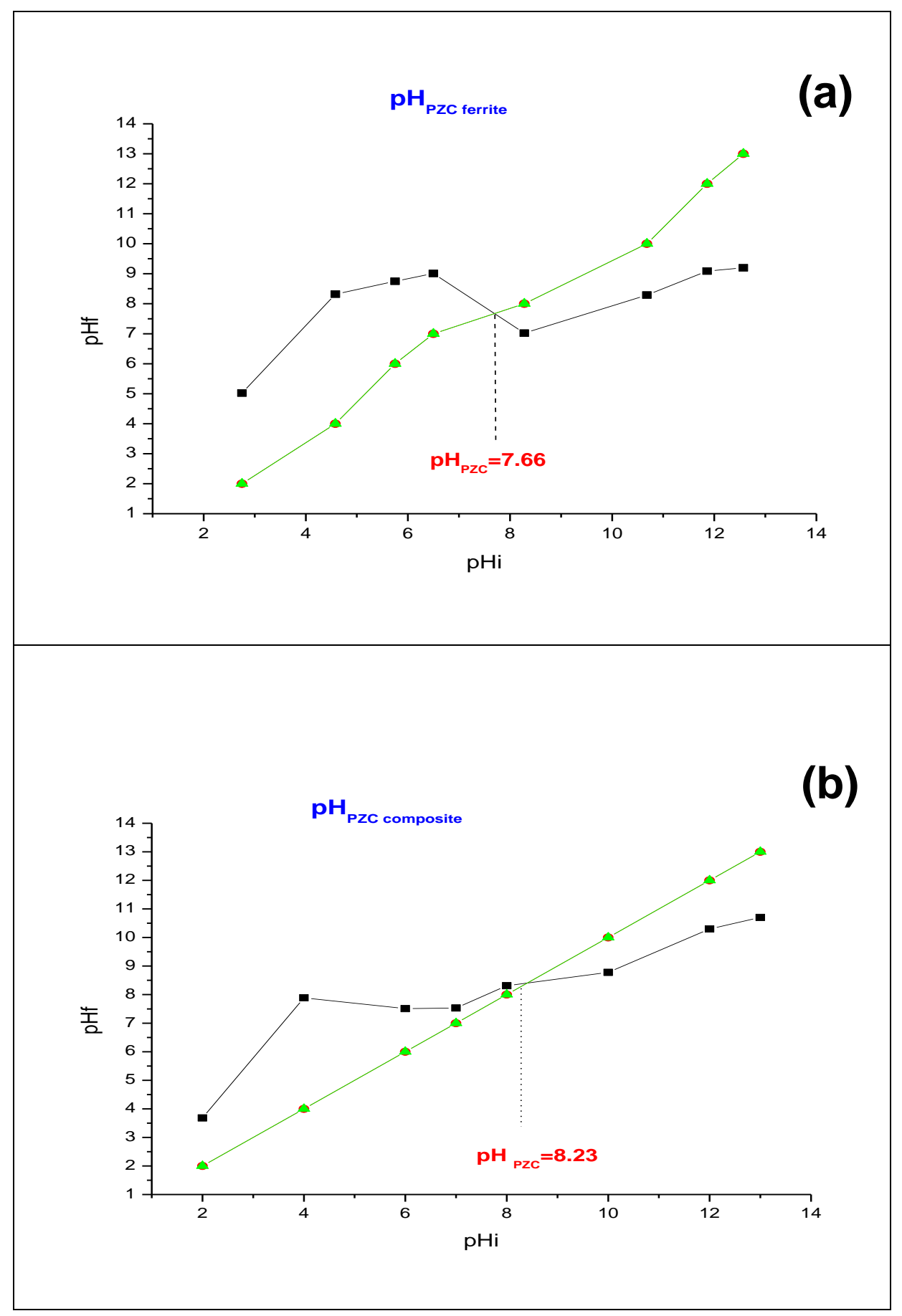

Figure 6. Zero charge point $\mathrm{pH}_{\mathrm{PZC}}$ of the $\mathrm{BiMgFeO}_{4}$ nanoferrite (a) and $\mathrm{BiMgFeO}_{4} / \mathrm{Bentonite}$ composite (b). 


\subsection{Batch adsorption experiments}

\subsubsection{Effect of initial pH on the adsorption of methyl orange}

Figure 7 displays the variation of the adsorbed amount of the $\mathrm{MO}$ anionic dye on $\mathrm{BiMgFeO}_{4}$ nanoferrite and on $\mathrm{BiMgFeO}_{4} /$ Bentonite composite versus $\mathrm{pH}$. High $\mathrm{MO}$ adsorption capacity can be noted at acidic $\mathrm{pH}$ values. This could be justified on the basis of the $\mathrm{pH}_{\mathrm{PZC}}$ which is $\sim 7,7$ for the obtained ferrite and $\sim 8.2$ for its composite.

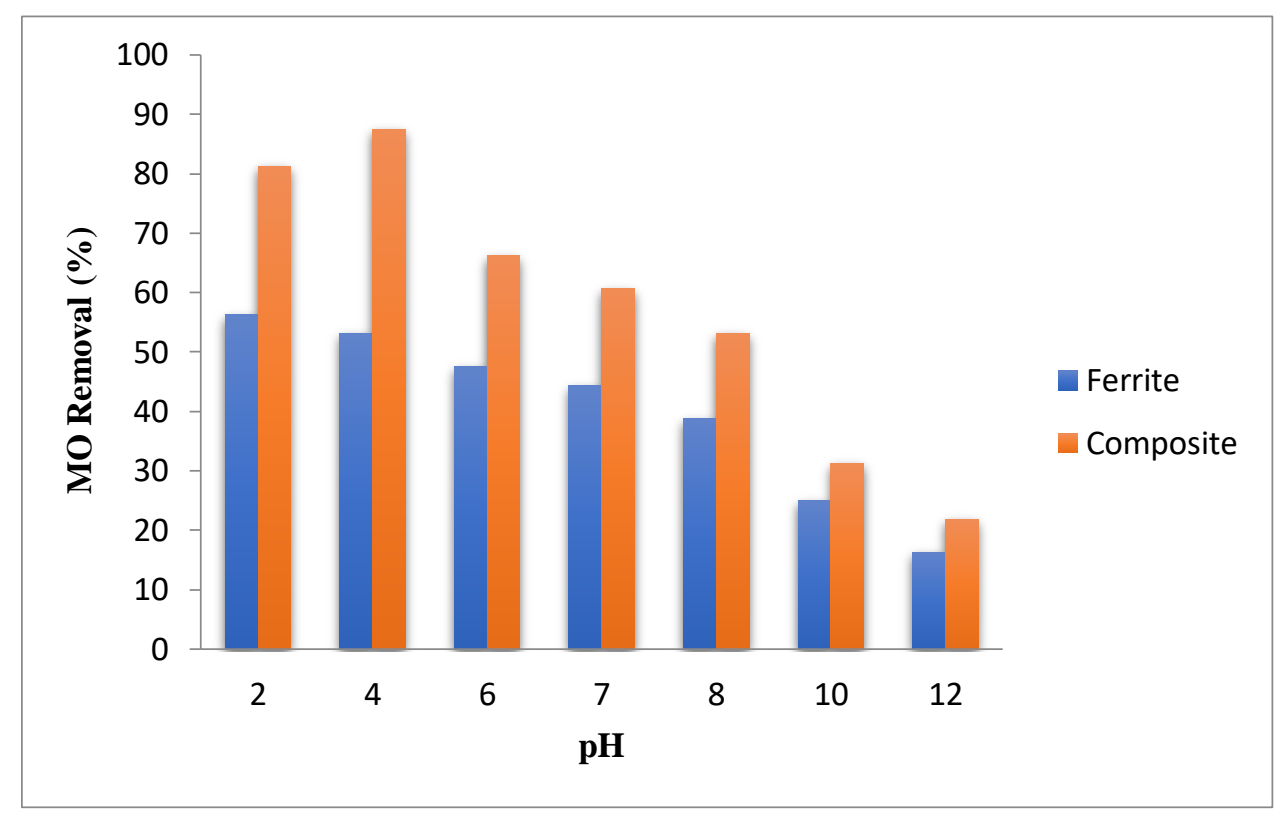

Figure 7. $\mathrm{pH}$ effect on the adsorption of methyl orange on the $\mathrm{BiMgFeO}_{4}$ nanoferrite ( $\square$ ) and the $\mathrm{BiMgFeO}_{4} /$ Bentonite composite ( $\square$ ).

\subsubsection{Effect of the adsorbent dose on the adsorption of Methyl Orange}

As shown in Figure 8, when adsorbent dose is increased, the MO removal efficiency increases, whereas the MO adsorption capacity decreases. As adsorption sites are fully available for MO at low adsorbent dose, resulting in a higher adsorption capacity. However, at high adsorbent dose, the majority of the low energy adsorption sites were occupied first. Consequently, the accessibility of highenergy adsorption sites is decreased and a reduction in adsorption capacity is achieved [50]. Additionally, the higher adsorbent dose increased the possibility of collisions and aggregation between solid particles, resulting in the decrease of the total surface area and ferrite adsorption capacity for MO. 
Increasing the mass of the adsorbent offers increased number of available adsorption sites and therefore increased amount of adsorbed dye [51]. While the decrease of MO adsorption could be explained by the saturation of adsorption sites [52]. However, the percentage of the solution dye decolorization is higher with the $\mathrm{BiMgFeO}_{4} / \mathrm{Bentonite}$ composite. It reached $92 \%$ for $1.5 \mathrm{~g}$ of adsorbent in $100 \mathrm{~mL}$ of solution, while it is $72 \%$ for $\mathrm{BiMgFeO}_{4}$ nano ferrite as adsorbent with the same dose.

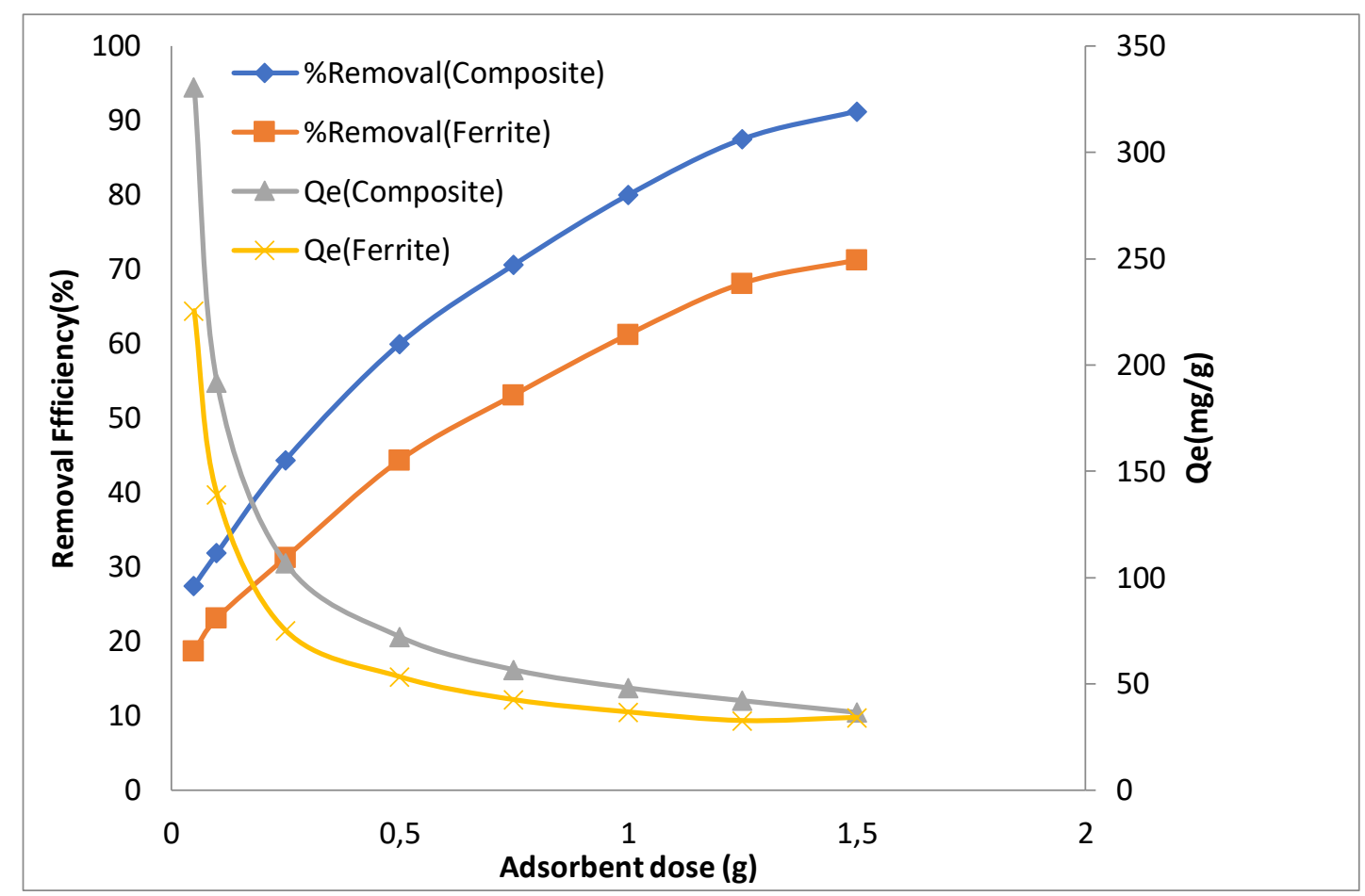

Figure 8. The effect of $\left(\mathrm{BiMgFeO}_{4}\right)$ nanoferrite and the $\left(\mathrm{BiMgFeO}_{4} /\right.$ Bentonite $)$ composite dose on the adsorption of Methyl Orange.

\subsubsection{Effect of the contact time on the absorption of methyl orange using nanoferrites}

The test of discoloration of $\mathrm{MO}$ by adsorption on the $\mathrm{BiMgFeO}_{4}$ ferrite and the ( $\mathrm{BiMgFeO}_{4} /$ Bentonite) composite (Figure 9) was carried out by following the contact time of the adsorption equilibrium, where a substrate saturation state is established. It is considered the most critical parameter in the development of an economical wastewater treatment system [53]. In fact, the 
contact time is fundamental for the determination of the maximum quantity of adsorption. The adsorption capacity or removal rate can be calculated from the Eq. (4)

$$
\% \text { Removal }=\frac{C_{0}-C_{t}}{C_{0}} \times 100
$$

With $\mathrm{C}_{0}$ : initial concentration and $\mathrm{C}_{\mathrm{t}}$ : concentration at time $\mathrm{t}$

As shown in Figure 9, when $\mathrm{BiMgFeO}_{4}$ nanoferrite is the adsorbent, the removal efficiency (\%) of $\mathrm{MO}$ increased as the contact time varied from 20 to $300 \mathrm{~min}$ before reaching a steady state. Therefore, 300 min was assumed as the equilibrium time. At this stage, the amount of dye desorbed from the adsorbent is in a dynamic equilibrium state with the amount of dye adsorbed on the adsorbents.

The adsorption is fast during the first minutes of the reaction, because at the beginning of adsorption, the number of active sites available on the surface of the adsorbent, is much more important than the number of sites remaining after a certain time. For high contact times the molecule needs time to diffuse inside the pore of the inside the pore of the adsorbent [54], for the rest of the quantity not adsorbed is interpreted by the saturation of the surface of the adsorbent (all the sites of adsorption are occupied).

On the other hand, the removal efficiency (\%) of $\mathrm{MO}$ dye by the $\mathrm{BiMgFeO}_{4} / \mathrm{Bentonite}$ composite increased as the contact time progressed to reach $180 \mathrm{~min}$ before becoming constant. Consequently, in this case, the equilibration time of $3 \mathrm{~h}$ is adequate since maximum adsorption is reached during this time. It is due to the aggregation of the dye particles with increasing contact time, which makes it almost impossible to diffuse deeper into the adsorbent structure at higher energy sites. This aggregation cancels out the influence of contact time as the pores fill in and begin to offer resistance to diffusion of aggregated dye molecules into the adsorbents [55]. The experimental results indicated that the optimal value of contact time for OM removal is lower with the composite. This fact proves that the addition of bentonite increases the percentage of dye adsorption and decreases the adsorption contact time. 


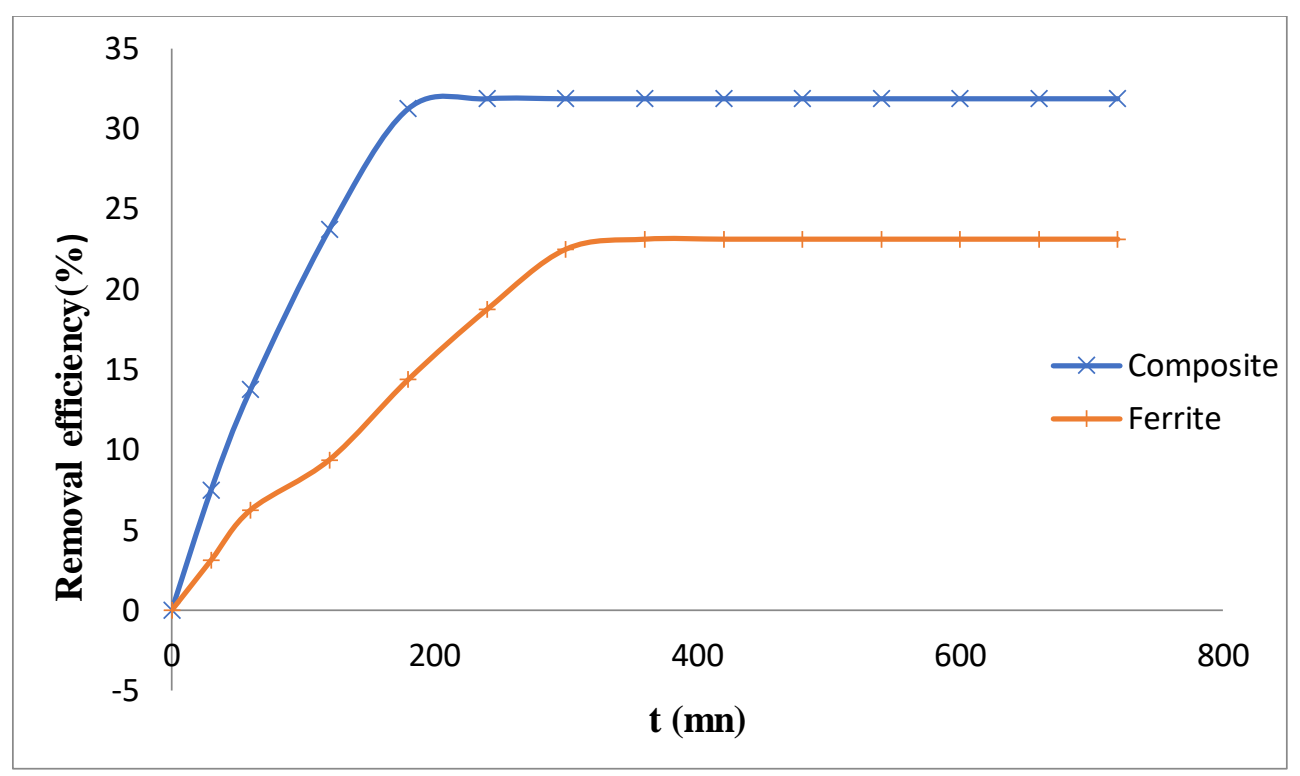

Figure 9. The effect of the contact time on the absorption of methyl orange by $\left(\mathrm{BiMgFeO}_{4}\right.$ ) nanoferrite and $\mathrm{BiMgFeO}_{4} /$ Bentonite composite

\subsubsection{Influence of the temperature on the absorption of methyl orange by nanoferrites}

Figure 10 displays the variation of temperature versus the removal efficiency $(\%)$ of methyl orange on $\mathrm{BiMgFeO}_{4}$ nanoferrite, and $\mathrm{BiMgFeO}_{4} /$ Bentonite composite. Rising temperature is known to increase the rate of diffusion of adsorbate molecules through the outer boundary layer and into the interior of the adsorbent particles, due to the decrease in the viscosity of the solution [56]. Figure 10 shows that the highest removal rate of the $\mathrm{MO}$ dye on $\mathrm{BiMgFeO}_{4}$ nanoferrite is $44.7 \%$ and occurs at $25{ }^{\circ} \mathrm{C}$. It is equal to $60.6 \%$ when $\mathrm{BiMgFeO}_{4} /$ Bentonite composite was used as adsorbent at the same temperature.

From the comparison of the two curves in Figure 10, room temperature is the most suitable temperature for the maximum removal of the methyl orange anionic dye by both materials. A rise in temperature is not favorable for the adsorption phenomenon, this could prove that it is an exothermic mechanism. 


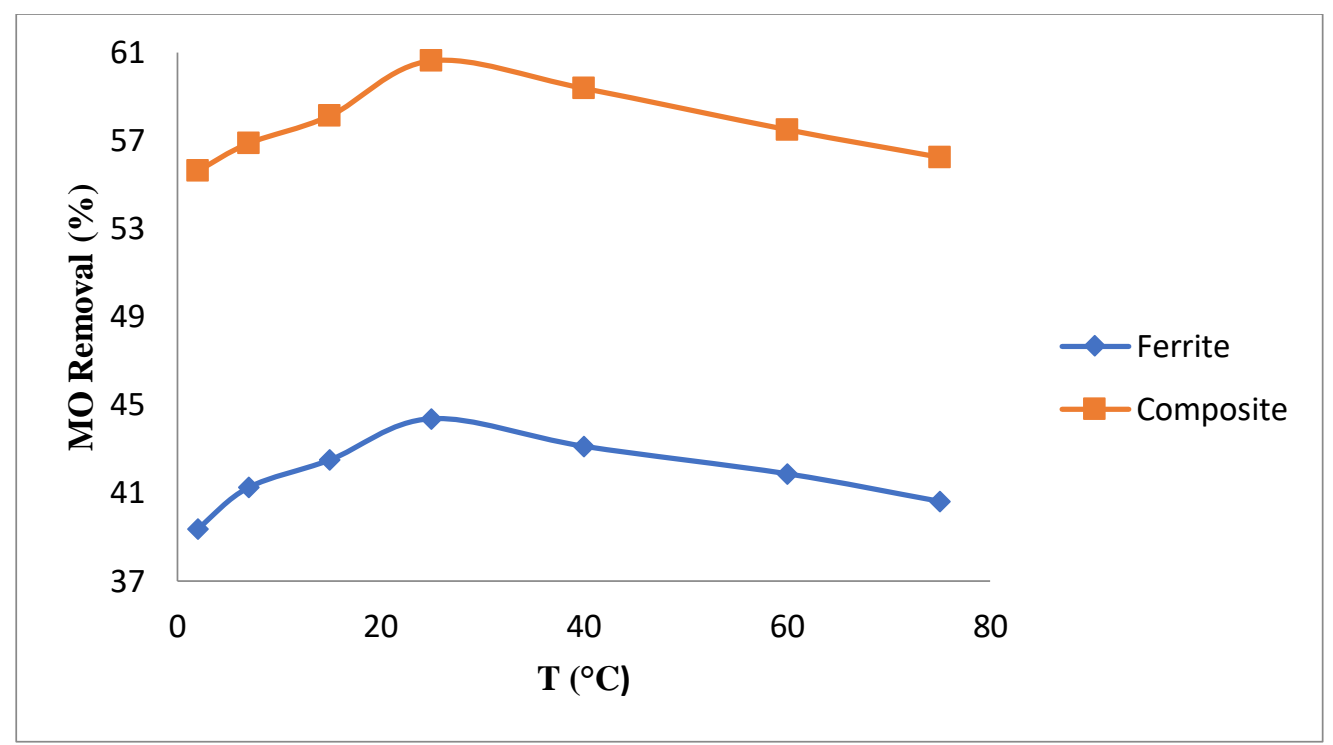

Figure 10. Effect of temperature on MO dye adsorption on the two adsorbents

\subsubsection{Adsorption Kinetics}

The thermodynamic equilibrium between the adsorbate in the liquid phase and the adsorbate fixed on the solid is achieved with a speed which depends not only on the speed with which the constituents diffuse in the adsorbent and in the fluid but also on the adsorbent-adsorbate interaction. The study of the dye adsorption on the nano ferrite as a function of time allows us to examine the influence of contact time on its retention.

For this purpose, two models have been applied to describe the mechanism of the adsorption kinetics of methylene blue on wood ash: the pseudo-first order (Eq. 5) and the pseudo-second order (Eq. 6) [57, 58]:

$$
\begin{aligned}
& \ln \left(\mathrm{Q}_{\mathrm{ads}}-\mathrm{Q}_{\mathrm{t}}\right)=\ln \mathrm{Q}_{\mathrm{ads}}-\mathrm{K}_{1} \mathrm{t} \\
& \frac{\mathrm{t}}{\mathrm{Q}_{\mathrm{t}}}=\frac{1}{\mathrm{Q}_{\mathrm{e}}^{2} \times \mathrm{K}_{2}}+\frac{\mathrm{t}}{\mathrm{Q}_{\mathrm{e}}}
\end{aligned}
$$

Qe (mg/g) is the equilibrium adsorption capacity, $\mathrm{Q}_{\mathrm{t}}(\mathrm{mg} / \mathrm{g})$ is the adsorption capacity at time $\mathbf{t}$ 
and $\mathbf{K}_{\mathbf{1}}\left(\mathrm{mn}^{-1}\right)$ constant of the pseudo-first order model. And $\mathbf{K}_{\mathbf{2}}\left(\mathrm{g} \cdot \mathrm{mg}^{-1} \cdot \mathrm{mn}^{-1}\right)$ constant of the pseudosecond order model.

The results reported in Table 2 show that for the pseudo-first order kinetic adsorption reaction on $\mathrm{BiMgFeO}_{4}$ ferrite and on $\mathrm{BiMgFeO}_{4} /$ Bentonite composite, the experimental adsorbed amount is different from the calculated one. Similarly, the values of correlation coefficient (Respectively $\mathrm{R}^{2}=$ 0.952 and 0.92 ) are slightly away from the unit. Therefore, the adsorption kinetic of the MO does not obey to a first order kinetic. In contrast, higher correlation coefficients $\mathrm{R}^{2}$, close to unit, were obtained for the ferrite and its composite $\left(\mathrm{R}^{2}=0.996\right.$ and 0.997 , respectively). The results better fit second order kinetic model for the adsorption of MO.

Table 2. Pseudo-first-order and pseudo-second-order models parameter

\begin{tabular}{|c|c|c|c|c|c|c|c|}
\hline \multirow{2}{*}{$\begin{array}{l}\text { Adsorbent } \\
(\mathrm{mg} / \mathrm{g}) \\
\end{array}$} & \multicolumn{4}{|c|}{ Pseudo-first order model } & \multicolumn{3}{|c|}{ Pseudo-second order model } \\
\hline & $\mathrm{R}^{2}$ & $\mathrm{~K} 1\left(\mathrm{mn}^{-1}\right)$ & $\mathrm{Q} 1(\mathrm{mg} / \mathrm{g})$. & $\mathrm{Q} \exp (\mathrm{mg} / \mathrm{g})$ & $\mathrm{R}^{2}$ & $\mathrm{~K} 2$ (g/mg./min) & Q exp. \\
\hline $\mathrm{BiMgFeO}_{4}$ & 0.952 & 0.0095 & 41.033 & 52.630 & 0.996 & 0.00058 & 56.179 \\
\hline \multicolumn{2}{|c|}{$\mathrm{BiMgFeO}_{4} /$ Bentonite 0.92} & 0.0239 & 96.892 & 72.931 & 0.997 & 0.00063 & 75.757 \\
\hline
\end{tabular}

The pseudo-first order constants were determined by extrapolation of the curve representing the variation of $\operatorname{Ln}\left(\mathrm{Q}_{\mathrm{e}}-\mathrm{Q}_{\mathrm{t}}\right)$ as a function of time $\mathrm{t}(\mathrm{mn})$ (Figure 11). 


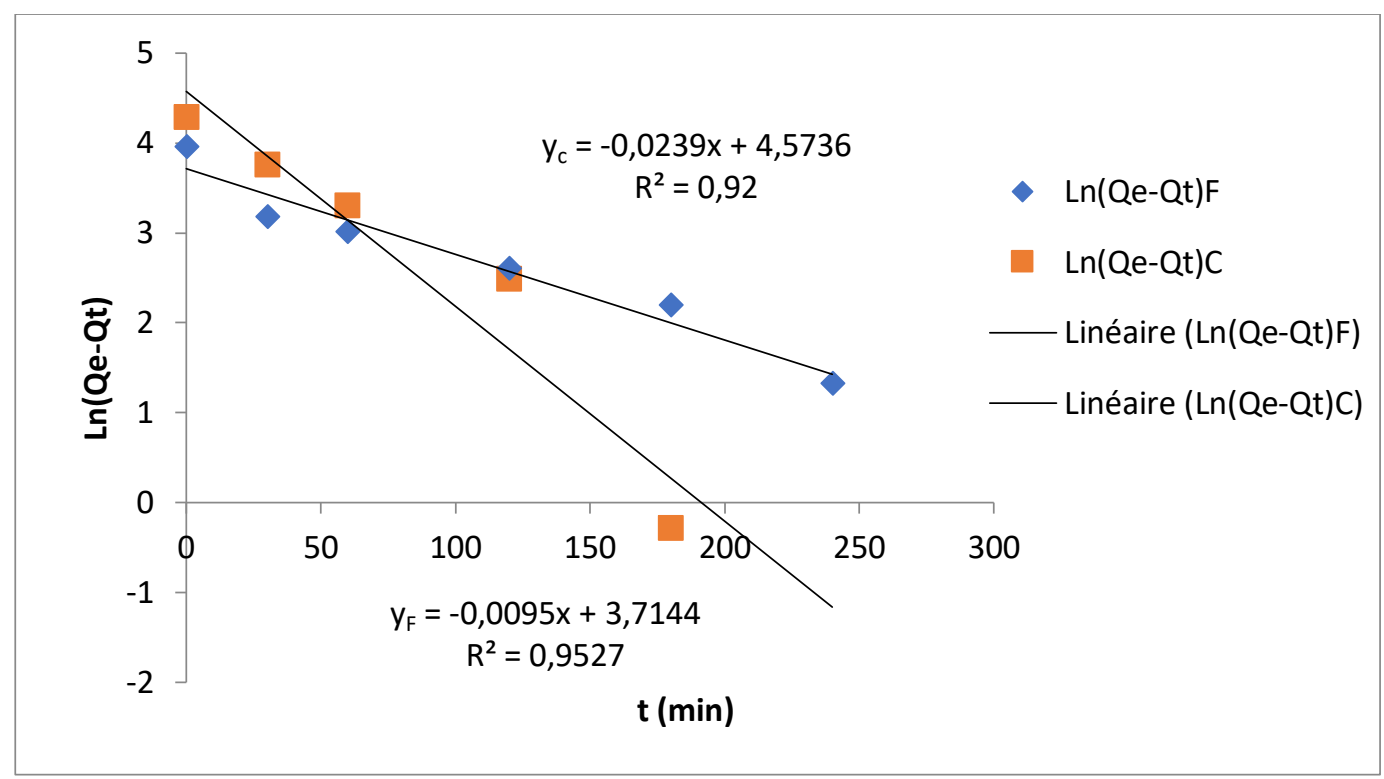

Figure 11. Pseudo-first order model applied to the adsorption of MO on the Ferrite and on the Composite

$\mathrm{C}=$ Composite $\quad \mathrm{F}=$ Ferrite

Otherwise, Figure 12 clearly illustrates the pseudo-second order kinetic model results for the adsorption of Methyl orange dye on the two adsorbents. The two quantities $\mathrm{K}_{2}$ constant of the pseudosecond order model, and Qe the adsorbed capacity at equilibrium, correspond respectively to the $y$ intercept and the slope of the line which represents the variation of $t / Q_{t}$ as a function of the time $t$ (min).

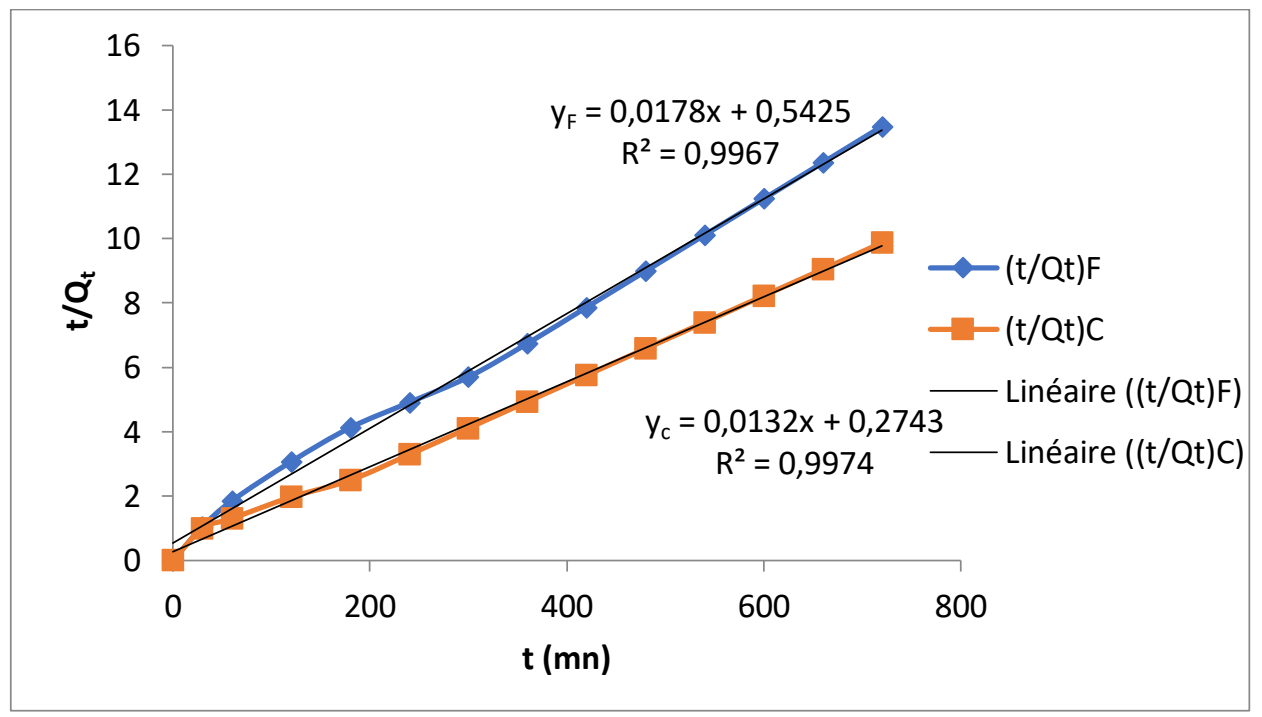

Figure 12. Pseudo-second order model applied to the adsorption of MO on the Ferrite and on the Composite. 


\subsubsection{Adsorption thermodynamics}

The adsorption thermodynamic constants are the standard enthalpy variation $\left(\Delta \mathrm{H}^{0}\right)$, the standard Gibbs free energy variation $\left(\Delta \mathrm{G}^{0}\right)$, and the standard entropy variation $\left(\Delta \mathrm{S}^{0}\right)$. They were calculated as following equations, Eq. (7) and Eq. (8) [59].

$$
\begin{aligned}
& \Delta \mathrm{G}_{0}=-\mathrm{RT} \ln \mathrm{K}_{\mathrm{L}} \\
& \ln \mathrm{K}_{\mathrm{L}}=\frac{\Delta \mathrm{S}_{0}}{\mathrm{R}}-\frac{\Delta \mathrm{H}_{0}}{\mathrm{RT}}
\end{aligned}
$$

Where $\mathrm{T}$ is the absolute temperature in Kelvin, $\mathrm{K}_{\mathrm{L}}\left(\mathrm{L} \cdot \mathrm{mol}^{-1}\right)$ as Langmuir's constant, $\mathrm{R}$ is the universal gas constant $\left(8.314 \mathrm{~J} \mathrm{~mol}^{-1} \mathrm{~K}^{-1}\right)$ and $\Delta \mathrm{H}^{0}$ and $\Delta \mathrm{S}^{0}$ are calculated from the linear plot slope and the intercept of $\ln \mathrm{K}_{\mathrm{L}}=\mathrm{f}(1 / \mathrm{T})$ (Figure 13). The $\Delta \mathrm{G}^{0}$ values established by the table below (Table 3) were negative. This indicated the thermodynamically spontaneous nature of the MO adsorption. With rising temperature, the values of standard free enthalpy variation decreased, it is a confirmation of the exothermic nature of the adsorption process.

The $\Delta \mathrm{H}^{0}$ values exposed in the Table 3 were negative indicating that the adsorption reaction of methyl orange (MO) on nano ferrite and composite was exothermic. Also, the positive values of $\Delta \mathrm{S}_{0}$ showed the increase in molecular disorder at the solid/liquid interface of the adsorption process and increase in degree of freedom of the adsorbed molecules. $\Delta \mathrm{H}_{0}$ and $\Delta \mathrm{S}_{0}$ are of opposite sign, therefore we do not observe a modification in the sign of the free enthalpy variation or a remarkable variation in its value by varying the temperature.

Table 3. Thermodynamic parameters for the adsorption of $\mathrm{MO}$ on the $\mathrm{BiMgFeO}_{4}$ ferrite and ( $\mathrm{BiMgFeO}_{4} / \mathrm{Bentonite}$ composite.

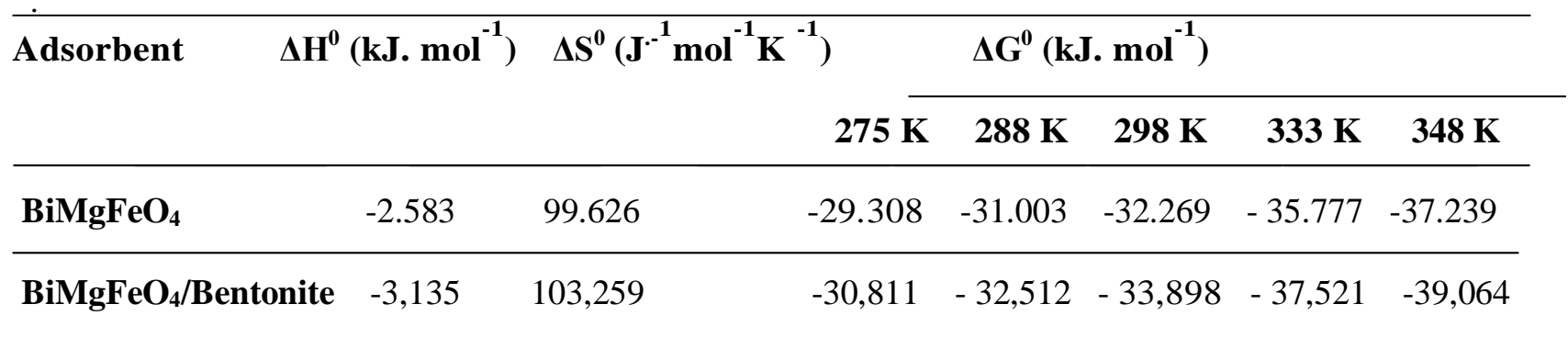




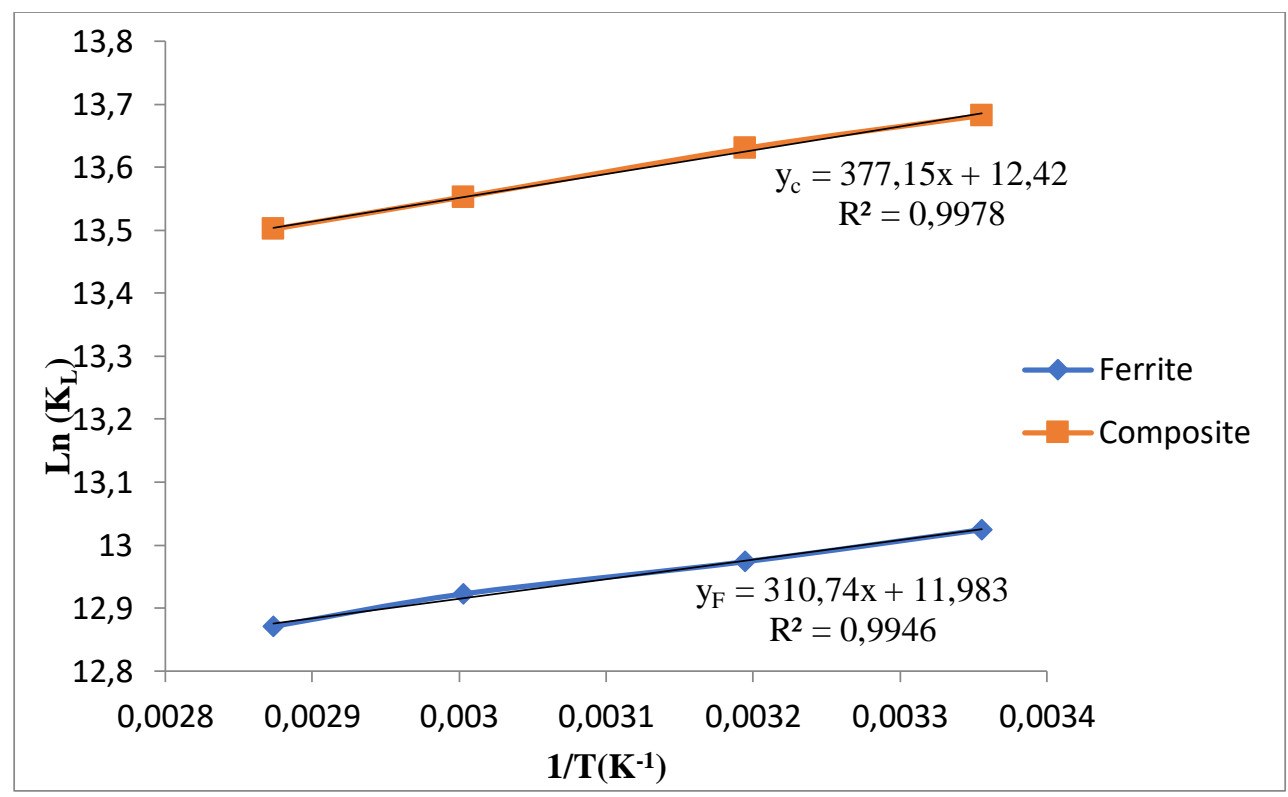

Figure 13. $\mathrm{Ln}\left(K_{L}\right)$ versus(1/T) for $\mathrm{MO}$ adsorption on $\mathrm{BiMgFeO}_{4}$ nanoferrite and on $\mathrm{BiMgFeO}_{4} /$ Bentonite composite

\subsubsection{Adsorption isotherm of methyl orange (OM)}

The experimental results were examined using Langmuir (Eq.9) and Freundlich (Eq.11) models. Langmuir isotherm model is one of the most frequently isotherms used for the adsorption in order to evaluate the maximum adsorption capacity of an adsorbate on an adsorbent. It requires that adsorption occurs on monolayer coverage of adsorbate over a homogenous adsorbent surface. Also, this model assumes that adsorption performs on specific homogeneous and energetically identical sites [60].

$$
\frac{1}{Q_{e}}=\frac{1}{Q_{m}}+\frac{1}{Q_{m} K_{L} C_{e}}
$$

where $K_{L}\left(L . m g^{-1}\right)$ is Langmuir equilibrium constant related to the affinity of adsorption, $Q_{m}\left(m g . g^{-1}\right)$ is the maximum adsorption capacity in monolayer, and $\mathrm{Ce}$ is the concentration at equilibrium.

The dimensionless equilibrium constant for the Langmuir isotherm can be expressed as (Eq. 10) [61]:

$$
\mathrm{R}_{\mathrm{L}}=\frac{1}{1+\mathrm{K}_{\mathrm{L}} \mathrm{C}_{0}}
$$


The separation factor, $R_{L}$ is defined by (Eq. 10) [62-66]. The adsorption isotherm is unfavorable when $\mathrm{R}_{\mathrm{L}}>1$, it is linear when $\mathrm{R}_{\mathrm{L}}=1$, it is favorable when $0<\mathrm{R}_{\mathrm{L}}<1$ and it is irreversible when " $\mathrm{R}_{\mathrm{L}}=0$ ".

The Freundlich model assumes heterogeneous surface energy. This model is widely used to describe multilayer adsorption [67]. The no-linear form of the Freundlich can be expressed as follows:

$$
\mathrm{LnQ}_{\mathrm{e}}=\operatorname{Ln} \mathrm{K}_{\mathrm{F}}+\frac{1}{\mathrm{n}} \mathrm{LnC}_{\mathrm{e}}
$$

where $K_{F}$ is the Freundlich constant (heterogeneity factor), and $1 / n$ is the Freundlich coefficient. $n$ is related to sorption affinity and $\mathrm{K}_{\mathrm{F}}$ is related to the sorption capacity. The efficiency of adsorption of an adsorbent is all the higher when the coefficient $n$ is between 1 and 10 [68-71].

The adsorption isotherms are shown in Figure 14 for both adsorbents, and the results of the modeling studies of the adsorption isotherms for the two models (Langmuir and Freundlich) and the correlation coefficients $\left(\mathrm{R}^{2}\right)$ are shown in the table below (Table 4). We observe that the Freundlich model $\left(\mathrm{R}^{2}=0.993\right)$ represents better the adsorption isotherms of $\mathrm{MO}$ on $\left(\mathrm{BiMgFeO}_{4}\right)$ nanoferrite than the Langmuir model $\left(\mathrm{R}^{2}=0.988\right)$. This suggests that the sites are heterogeneous, with the possibility of more than one adsorption monolayer on the ferrite surface.

Table 4. Adsorption Equilibrium parameters for Langmuir and Freundlich Isotherms.

\begin{tabular}{lccccc}
\hline \multicolumn{2}{l}{ Langmuir Isotherm parameters } & & \multicolumn{2}{c}{ Freundlich Isotherm parameters } \\
\hline Item & BiMgFeO4 & BiMgFeO4/Bentonite & Item & BiMgFeO $4^{\text {BiMgFeO4/Bentonite }}$ \\
\hline & & & & & \\
Qm (mg/g) & 181.812 & 188.679 & $1 / \mathrm{n}$ & 0.7011 & 0.3234 \\
$\mathrm{~K}_{\mathrm{L}}(\mathrm{L} / \mathrm{g})$ & 0.1087 & 0.1325 & $\mathrm{~K}_{\mathrm{f}}(\mathrm{L} / \mathrm{g})$ & 18.383 & 22.0409 \\
$\mathrm{R}_{\mathrm{L}}$ & 0.1554 & 0.131 & $\mathrm{R}^{2}$ & 0.993 & 0.985 \\
$\mathrm{R}^{2}$ & 0.988 & 0.9931 & & & \\
\hline
\end{tabular}

On the other hand, when $\mathrm{BiMgFeO}_{4} /$ Bentonite is the adsorbent, we observe that the correlation coefficients are close to unit $\left(\mathrm{R}^{2}=0.993\right)$ in the Langmuir model and $\left(\mathrm{R}^{2}=0.985\right)$ for the Freundlich model. We conclude that the Langmuir model is the most consistent with the experimental data. The $\mathrm{n}$ value of the Freundlich model calculated for the two adsorbents are always between 0 and 1 . These results verify that the adsorption process of $\mathrm{MO}$ on the composite is favorable. 

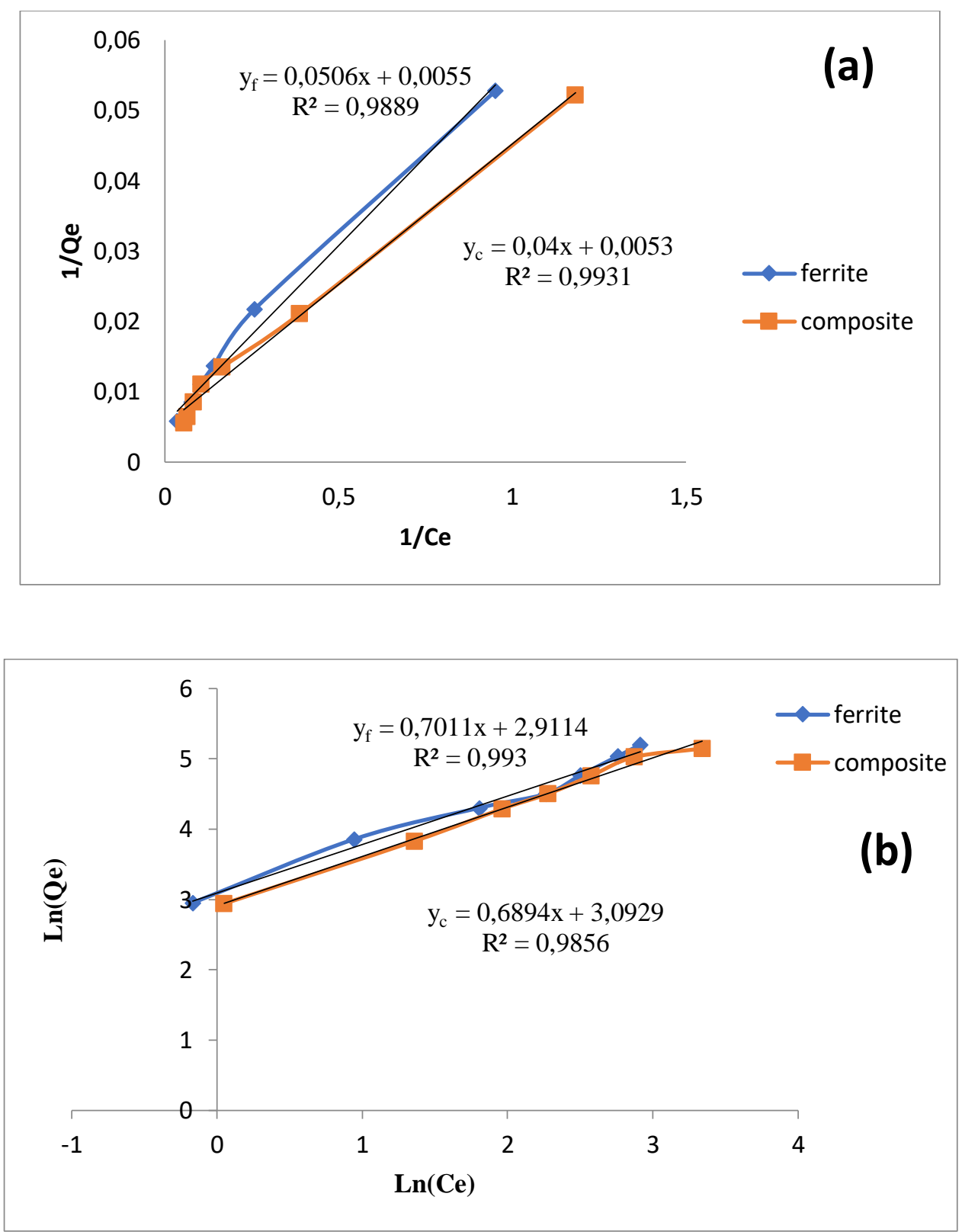

Figure 14. Langmuir (a) and Freundlich (b) isotherms for the adsorption of MO on ferrite $(\diamond)$ and composite $(\square)$.

\subsubsection{Isosteric heat of adsorption}

The isosteric heat of adsorption $\mathrm{Q}_{\mathrm{st}}\left(\mathrm{kJ} \cdot \mathrm{mol}^{-1}\right)$ is the amount of heat developed during the adsorption of one mole of MO dye by one gram of adsorbent. It was determined at constant amount of adsorbate adsorbed $\left(\mathrm{Qe}=30,32,34,36,38 \mathrm{mg} \cdot \mathrm{g}^{-1}\right)$ and was calculated using the Clausius-Clapeyron equation given by the following relation where $\Delta \mathrm{H}_{\mathrm{ads}}=-\mathrm{Q}_{\mathrm{st}}$

$$
\frac{d(\ln C e)}{d t}=-\frac{\Delta H_{a d s}}{R T^{2}}
$$




$$
\operatorname{Ln}(C e)=\frac{\Delta H_{a d s}}{R T}+\text { constant }
$$

For this purpose, the equilibrium concentration $(\mathrm{Ce})$ at constant amount of Methyl orange adsorbed was obtained from the isotherm data at different temperatures. The values of $\Delta \mathrm{H}_{\text {ads }}$ were obtained from the slope of a plot of Ln Ce versus 1/T for different amounts of adsorbate onto the two adsorbents separately. The plots of $\mathrm{Ln}$ Ce versus $1 / \mathrm{T}$ were found to be linear (Figure 15), and the values of $\Delta \mathrm{H}_{\mathrm{ads}}$ were measured from the slopes of the plots.

The $\mathrm{R}^{2}$ values of the isosteres and the corresponding $\Delta \mathrm{H}_{\mathrm{ads}}$ values for the adsorption of MO on the two prepared adsorbents are listed in the following table (Table 5) at different values of the amount of Methyl orange adsorbed at equilibrium Qe (mg. $\left.\mathrm{g}^{-1}\right)$.

Table 5. Isosteric heat of adsorption of $\mathrm{MO}$ onto $\mathrm{BiMgFeO}_{4}$ nanoferrite and on $\mathrm{BiMgFeO}_{4} / \mathrm{Bentonite}$ composite

\begin{tabular}{|c|c|c|c|c|}
\hline Adsorbent & \multicolumn{2}{|c|}{ BiMgFeO $_{4}$} & \multicolumn{2}{|c|}{ BiMgFeO4/Bentonite } \\
\hline $\mathbf{Q}_{\mathbf{e}}(\mathbf{m g} / \mathbf{g})$ & $\Delta \mathrm{H}_{\text {ads }}\left(\mathrm{kJ}_{\mathbf{M o l}}{ }^{-1}\right)$ & $\mathrm{R}^{2}$ & $\Delta \mathrm{H}_{\text {ads }}\left(\mathrm{kJ}_{\mathrm{Mol}}{ }^{-1}\right)$ & $\mathrm{R}^{2}$ \\
\hline $\mathbf{3 0}$ & $-1,100$ & 0,973 & $-2,88$ & 0,998 \\
\hline $\mathbf{3 2}$ & $-1,094$ & 0,973 & $-2,87$ & 0,991 \\
\hline $\mathbf{3 4}$ & $-1,092$ & 0,998 & $-2,70$ & 0,995 \\
\hline $\mathbf{3 6}$ & $-1,085$ & 0,990 & $-2,56$ & 0,999 \\
\hline $\mathbf{3 8}$ & $-1,081$ & 0,986 & $-2,5$ & 0,991 \\
\hline
\end{tabular}

The Figure $15 \mathrm{a}$ displays the variation of $\mathrm{Ln} \mathrm{Ce}$ versus $1 / \mathrm{T}$ for different amounts of $\mathrm{BiMgFeO}_{4}$ nanoferrite, and Figure $15 \mathrm{~b}$ displays the variation of $\mathrm{Ln}$ Ce versus 1/T for different amounts of adsorbate for adsorption of $\mathrm{MO}$ onto $\mathrm{BiMgFeO}_{4} / \mathrm{Bentonite}$ composite. 

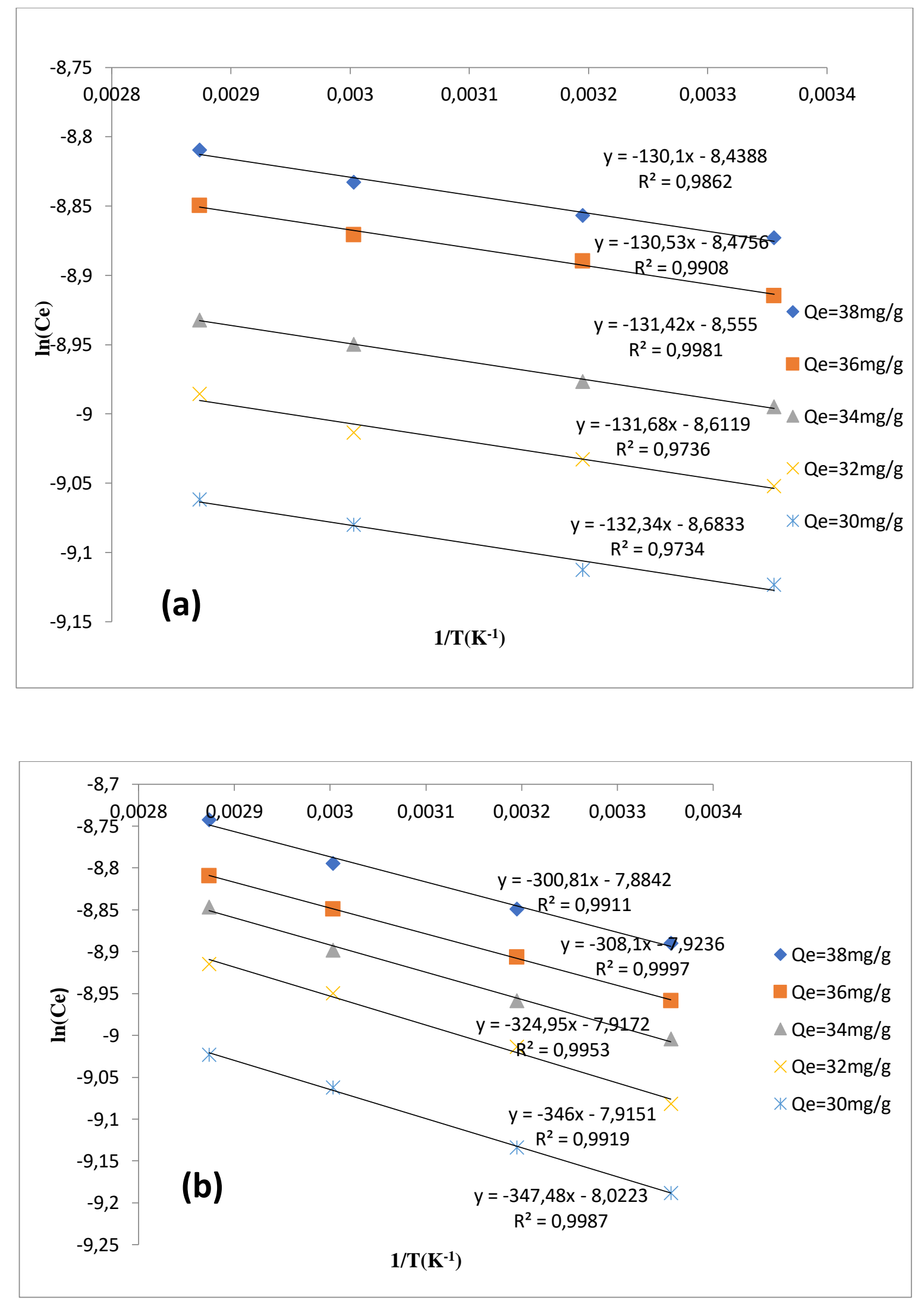

Figure 15. Plots of $\ln \mathrm{Ce}$ versus $1 / \mathrm{T}$ for adsorption of $\mathrm{MO}$ onto $\mathrm{BiMgFeO}_{4}$ nanoferrite (a), and $\mathrm{BiMgFeO}_{4} /$ Bentonite composite (b). 
The negative values of isosteric heat of adsorption confirm the exothermic adsorption process. Moreover, the heat of physical adsorption, which involves only relatively weak intermolecular forces such as van der Waals and electrostatic interactions, is low compared to that of chemisorption, which involves essentially the formation of a chemical bond between molecules adsorbate and the surface of the adsorbent. The upper limit for $\mathrm{Q}_{\text {st }}$ physical adsorption called physisorption should be $80 \mathrm{~kJ} \mathrm{~mol}^{-1}$ for adsorption on adsorbents and for chemical adsorption (chemisorption) (characterized by covalent bonding) it ranges between (80 and 400) $\mathrm{kJ} \mathrm{mol}^{-1}$ [72]. In the present work, the values of isosteric heat of methyl orange adsorption range between 1.081 and $1.1 \mathrm{~kJ}^{-\mathrm{mol}^{-1}}$ for the prepared ferrite, and between 2.5 and $2.88 \mathrm{~kJ}^{-1} \mathrm{~mol}^{-1}$ for its composite.

The results above show that the interaction between the surface of both (Mg-doped bismuth ferrite) and its composite (Mg-doped bismuth ferrite-bentonite) and MO dye molecules is a physisorption, involving weak van der Waals and electrostatic interactions.

\section{Conclusion}

This study demonstrated the effectiveness of nano adsorbent based on magnetic ferrite (Mg-doped bismuth ferrite) and its clay-based Mg-doped bismuth ferrite-bentonite in removing methyl orange dye in aqueous medium. Adsorbents were prepared by self-combustion method utilizing the glycine approach as fuel. The influence of parameters related to operating conditions such as contact time, amount of adsorbent, $\mathrm{pH}$, and temperature were examined.

Increasing the adsorbent mass generated an increase of the adsorption capacity of the anionic dye for both adsorbents. However, the percentage of the solution dye decolorization is higher with the (BiMgFeO $4 /$ Bentonite) composite. It reached $\sim 91.3 \%$ for $150 \mathrm{mg}$ of adsorbent in $100 \mathrm{~mL}$ of solution, while it is $\sim 71.3 \%$ for $\left(\mathrm{BiMgFeO}_{4}\right)$ nanoferrite as adsorbent with the same dose. Moreover, acidic $\mathrm{pH}$ is the optimal medium to have a better adsorption of the MO anionic dye on both adsorbents.

The kinetic study shows that the equilibrium is established after 300 minutes for the $\mathrm{Mg}$-doped bismuth ferrite, while it is established after 180 minutes for the $\mathrm{BiMgFeO}_{4} / \mathrm{Bentonite}$ composite. Moreover, the adsorption mechanism can be described by pseudo-second order kinetic for both the prepared ferrite and its composite.

The plot of the adsorption isotherms confirms that the adsorption process of methyl orange on both the ferrite and its composite is favorable. The Freundlich model perfectly represents adsorption of MO dye to the prepared Mg-doped bismuth ferrite with a maximum adsorption capacity of 181.8 
mg. $\mathrm{g}^{-1}$ at $298 \mathrm{~K}$ and $\mathrm{pH} \sim 6.9$. This suggests that the sites are heterogeneous, with the possibility of more than one adsorption monolayer on the ferrite surface. While, Langmuir model seems to be the most suitable model for the absorption of methyl orange to the $\mathrm{Mg}$-doped bismuth-bentonite composite, with a maximum adsorption capacity of $188.79 \mathrm{mg} \cdot \mathrm{g}^{-1}$ at $298 \mathrm{~K}$ and $\mathrm{pH}=6.85$. For both adsorbents, the $\mathbf{n}$ value of the Freundlich model, related to the adsorption intensity and surface heterogeneity provides evidence that the adsorption is favorable. $\mathbf{n}$ being higher in the case of the composite than with the ferrite, indicating that the adsorption of MO dye is higher on the composite.

It has also been proven that the composite has a mesoporous structure which is favorable for the elimination of the MO anionic dye.

The thermodynamic parameters indicate that the adsorption of methyl orange is an exothermic process with random distribution of MO dye molecules over the adsorbent surface.

The determination of isosteric heat of adsorption for both prepared adsorbents suggested that it is indeed a physisorption characterized by weak intermolecular forces between adsorbate and the surface of the adsorbent.

Declaration of interest: the authors declare no conflict of interest.

\section{References}

[1] S. Sharma, A. Kaur, Various Methods for Removal of Dyes from Industrial Effluents A Review, 11 (2018).

[2] A. Ahmad, M. Rafatullah, O. Sulaiman, M.H. Ibrahim, R. Hashim, Scavenging behaviour of meranti sawdust in the removal of methylene blue from aqueous solution, 170 357-365,(2009).

[3] W. Zhang, H. Yan, H. Li, Z. Jiang, L. Dong, X. Kan, Removal of dyes from aqueous solutions by straw based adsorbents : Batch and column studies, Chem. Eng. J. 168 1120-1127,(2011).

[4] Ã. Bee, V. Rocher, J. Siaugue, Removal of organic dyes by magnetic alginate beads, 42 1290-1298,(2008).

[5] K. Bing, M. Vakili, B. Amini, P. Eong, A. Zuhairi, B. Salamatinia, Adsorption of dyes by nanomaterials : Recent developments and adsorption mechanisms, Sep. Purif. Technol. 150 229-242,(2015).

[6] C. Removal, F. Textile, COLOR REMOVAL FROM TEXTILE, 34 9-16,(1996).

[7] K. Panchamoorthy, S. Murugesan, J. Abraham, K. Muthukumar, Bioresource Technology Bacillus sp . mutant for improved biodegradation of Congo red : Random mutagenesis approach, Bioresour. Technol. 100 6295-6300,(2009).

[8] G. Ciardelli, L. Corsi, M. Marcucci, Membrane separation for wastewater reuse in the textile industry, 31 189-197, (2000). 
[9] D. Mantzavinos, E. Psillakis, Enhancement of biodegradability of industrial wastewaters by chemical oxidation pre-treatment, 454 431-454, (2004).

[10] R. Dhahri, A. Bouzidi, Y. Moussaoui, Activated Carbon from Prickly Pear Seeds:

Optimization of Preparation Conditions and Cadmium Removal Using Experimental Design Approach, in: 2021: pp. 1457-1461,(2021).

[11] R. Jayalakshmi, J. Jeyanthi, PT NU SC, Microchem. J. (2018)

[12] Z. Huang, P. Gao, H. Zheng, X. Liu, J. Wen, Magnetic enrichment behavior of monodispersed MFe $2 \mathrm{O} 4$ nanoferrites ( $\mathrm{M}=\mathrm{Mg}, \mathrm{Ca}, \mathrm{Ni}, \mathrm{Co}$, and $\mathrm{Cu}$ ), Ceram. Int. 45 15980-15989,(2019).

[13] P. Chand, S. Vaish, P. Kumar, Structural, Optical and Dielectric Properties of Transition Metal ( MFe $2 \mathrm{O} 4 ; \mathrm{M}=\mathrm{Co}, \mathrm{Ni}$ and $\mathrm{Zn}$ ) Nanoferrites Structural, optical and dielectric properties of transition metal ( $\mathrm{MFe} 2 \mathrm{O} 4 ; \mathrm{M}=\mathrm{Co}$, Ni and $\mathrm{Zn}$ ) nanoferrites, Phys. B Phys. Condens. Matter. 524 53-63,(2017).

[14] Z. Lu, P. Gao, R. Ma, J. Xu, Z. Wang, E. V Rebrov, Structural, magnetic and thermal properties of one-dimensional CoFe2O4 microtubes, J. Alloys Compd. (2016).

[15] X. Pan, A. Sun, Y. Han, W. Zhang, X. Zhao, Structural and magnetic properties of Bi $3+$ ion doped $\mathrm{Ni}-\mathrm{Cu}-\mathrm{Co}$ nano ferrites prepared by sol - gel auto combustion method, J. Mater. Sci. Mater. Electron, (2019).

[16] A. Pathania, K. Rana, N. Bhalla, P. Thakur, “ ssbauer spectroscopic studies of tungsten doped Raman and Mo Ni - Zn nano ferrite, J. Mater. Sci. Mater. Electron. 28 679685,(2017).

[17] I.H. Gul, A. Sutka, S. Lagzdina, Structural and Dielectric Properties of Bismuth Doped Cobalt Nano Ferrites Prepared by Sol-Gel Auto Combustion Method Structural and Dielectric Properties of Bismuth Doped Cobalt Nano Ferrites Prepared by Sol-Gel Auto Combustion Method, 0-11, (2017).

[18] S.F. Mansour, R. Al-wa, M.A. Abdo, Zn-Mg-La nanoferrites for storage and high frequency devices with augmenting the photocatalytic performance, 826 (2020).

[19] S. Taneja, D. Chahar, P. Thakur, A. Thakur, Jo ur na 1 P re of, J. Alloys Compd. (2020)

[20] S. Singh, P. Kaur, V. Kumar, K.B. Tikoo, S. Singhal, na of, J. Rare Earths. (2020).

[21] A. Camacho-gonz, A. Garrido-, M.F. Ramírez-ayala, L. Esperanza, Synthesis and characterization of magnetic zinc-copper ferrites : Antibacterial activity, photodegradation study and heavy metals removal evaluation, 236 (2019).

[22] J. Pre-proofs, Significantly improved solar photodegradation of water pollutant by new plate-like bismuth ferrite nanoparticles tuned by gelatin, Elsevier B.V., (2020).

[23] T. Tatarchuk, M. Myslin, I. Lapchuk, A. Shyichuk, A.P. Murthy, R. Gargula, P.

Kurzydło, B.F. Bogacz, A.T. Pędziwiatr, Magnesium-zinc ferrites as magnetic adsorbents for Cr(VI) and $\mathrm{Ni}(\mathrm{II})$ ions removal: Cation distribution and antistructure modeling, Chemosphere. 270 129414,(2021).

[24] S. Naz, T. Rasheed, S. Tayyab, R. Naqvi, D. Hussain, B. Fatima, M. Najam

S.Majeed,,S. Shafi, K. Rizwan, M. Ibrahim, Physica B : Physics of Condensed Matter

Polyvinylpropyllidone decorated manganese ferrite based cues for the efficient removal of heavy metals ions from waste water, Phys. B Phys. Condens. Matter. 599 412559, (2020).

[25] S. Caille`re, S. He'nin, M. Rautureau, Mine'ralogie des argiles : Structure et propriétes

Physico chimiques Tome II, Edition Masson, Paris, (1982).

[26] A. Bouchet, A. Meunier, P. Sardini, Mine'raux argileux, Edition Eyrolles, 2000.

[27] Elkhider, K.H.A., Ihsanullah, I., Zubair, M. et al. Synthesis, characterization and dye adsorption performance of a magnetic bentonite-CoNiAl composite decorated Bentonite-CoNiAl Magnetic Composite. Arab J Sci Eng 45, 7397-7408 (2020) 
[28] M.M.S. Sanad, M.M. Farahat, M.A. Abdel Khalek, One-step processing of low-cost and superb natural magnetic adsorbent: kinetics and thermodynamics investigation for dye removal from textile wastewater, Advanced Powder Technology,(32)5,1537-1583(2021)

[29] Zhang, H., Liang, X., Yang, C., Niu, C., Wang, J., \& Su X, Nano $\gamma$-Fe 2 O 3 /bentonite magnetic composites: Synthesis, characterization and application as adsorbents,Journal of Alloys and Compounds, 688, 1019-1027, (2016).

[30] An S, Liu X, Yang L \& Zhang L, Enhancement removal of crystal violet dye using magnetic calcium ferrite nanoparticle: Study in single- and binary-solute systems, Chemical Engineering Research and Design, 94, 726- 735 (2015)

[31] K.H. Wu, T.H. Ting, M.C. Li, W.D. Ho, Sol - gel auto-combustion synthesis of SiO 2 -doped NiZn ferrite by using various fuels, 298 25-32, (2006).

[32] Housseina Nasri1 , Saci Kermani2 ,Mohamed Ammar Abbassi1 and Ahmed Omri1, Characterization of Sand From Jebel Ad-Darin Sened (Gafsa-Tunisia), September (2020). [33] U. Bhasker, V. Yelasani, V. Ramana, R. Musugu, Journal of Magnetism and Magnetic Materials Structural, electrical and magnetic characteristics of nickel substituted cobalt ferrite nano particles, synthesized by self combustion method, J. Magn. Magn. Mater. 374 (2015) [34] A.U. Rehman, N.A. Morley, N. Amin, M.I. Arshad, M.A. un Nabi, K. Mahmood, A. Ali, A. Aslam, A. Bibi, M.Z. Iqbal, F. Iqbal, N. Bano, M. Alzaid, Controllable synthesis of $\mathrm{La} 3+$ doped $\mathrm{Zn} 0.5 \mathrm{Co} 0.25 \mathrm{Cu} 0.25 \mathrm{Fe} 2-\mathrm{xLaxO} 4(\mathrm{x}=0.0,0.0125,0.025,0.0375,0.05)$ nanoferrites by sol-gel auto-combustion route, Ceram. Int. 46 29297-29308,(2020).

[35] Newcombe, G., Hayes, R., Drikas, M. Granular activated carbon: Importance of surface proprieties in the adsorption of naturally occurring organics. Colloids and Surfaces A:

Physicochemical and Engineering Aspects, 65-71. (1993)

[36] X. Guo, J. Wang, Comparison of linearization methods for modeling the Langmuir adsorption isotherm, J. Mol. Liq. 296 111850,(2019).

[37] H. Freundlich, Über die Adsorption in Lösungen 1 ), 1334 (1899).

[38] A.M. Shaikh, S.A. Jadhav, S.C. Watawe, B.K. Chougule, Infrared spectral studies of Zn-substituted Li - Mg ferrites, 192-196,(2000).

[39] M. Abbas, B.P. Rao, S.M. Naga, M. Takahashi, C. Kim, Author's Accepted Manuscript, Ceram. Int. (2013).

[40] S.R.Dhanya,SoumyaG.Nair,Jyotirmayee Satapathy, and N.Pavan Kumar"Structural and spectroscopie characterization of bismuth ferrite"AIP Conference Proceedings(2019)2166,020017 [41] J Peñalva1 and A Lazo Synthesis of Bismuth Ferrite BiFeO3 by solution combustion Method IOP Conf. Series: Journal of Physics: Conf. Series 1143 012025,(2018)

[42] J Peñalva, A Lazo - Journal of Physics: Conference Synthesis of Bismuth Ferrite BiFeO

3 by solution combustion method, Series, (2018).

[43] Zhenxing Yue, Wenyu Guo, Ji Zhou, Zhilun Gui, Longtu Li, Synthesis of nanocrystilline ferrites by sol-gel combustion process: the influence of $\mathrm{pH}$ value of solution , Journal of Magnetism and Magnetic Materials,216-223,(2004)

[44] Yen-Chun Liu a, Yen-Pei Fu b , Magnetic and catalytic properties of copper ferritenanopowders prepared by a microwave-induced combustion process, Ceramics International 36 1597-1601,(2010)

[45] Thommes, M., Cychosz, K.A. Physical adsorption characterization of nanoporous materials: progress and challenges. Adsorption 20, 233-250 (2014)

[46] Kenneth Sing, Review about The use of nitrogen adsorption for the characterisation of porous materials, Colloids and Surfaces A: Physicochemical and Engineering Aspects 187-188 3-9,(2001)

[47] Lev D. Gelb and K. E. Gubbins Langmuir 15 (2), 305-308, 1999

[48] David Mihayo, Maheswara Rao Vegi, Said Ali Hamad Vuai, "Defluoridation of Aqueous 
Solution Using Thermally Activated Biosorbents Prepared from Adansonia digitata Fruit Pericarp", Adsorption Science; Technology, vol. 2021, Article ID 5574900, ,16 pages, (2021)

[49] F. Stoeckli, M.V. Moreno Ramon, C. Moreno-Castilla, C. Carrasco Castilla, Carrasco

Marin, Carbon 37 1215-1221,(1999).

[50] Shao Y, Wang X, Kang Y et al ,Application of Mn/ MCM-41 as an adsorbent

to remove methyl blue from aqueous solution. J Colloid Interface Sci 429:25-33, (2014)

[51] B.H. Hameed, Evaluation of papaya seed as a novel non-conventional low-cost adsorbent for removal of methylene blue, J. Hazard. Mater. 162 939-994,(2010)

[52] A.K. Patil, V.S. Shrivastava, Alternanthera bettzichiana plant powder as low cost

Adsorbent for removel of congo red from aqueous solution, Int. J. Chemtech Res. 2

842-850, (2010)

[53] R. Centre, Adsorption of Lead from Aqueous Solution by Manganese Ferrite Nanoparticles, 25 9920-9926. (2013)

[54] A.R. Dincer, Y. Guner, N. Karakaya. Coal-based botton ash (CBBA) waste material as adsorbent for removal of textile dyestuffs from aqueous solution, Colloid and interface, Science 293,303-311 (2006).

[55]. Mall ID, Srivastva VC, Agarwal NK, Mishra IM , Removal of Congo red from aqueous solution by baggase fly ash and activated carbon: kinetic study and equilibrium isotherm analyses. Chemosphere 61:492-501,(2005)

[56] M. Dogan, M. Alkan, O. Demirabas, Y. Ozedemie, C. Ozemetin. Adsorption kinetics of maxilon blue GRL onto sepiolite from aqueous solution, Chemical Engineering Journal, 124 89-101,(2006)

[57] S. Lagergren, Zur theorie der sogenannten adsorption geloester stoffe. Kungliga

Svenska Vetenskapsakad, Handlingar 24 1-39,(1898)

[58] Y.S. Ho, G. Mckay, Pseudo-second order model for sorption processes, 34 451-465, (1999).

[59] Z. Luo, M. Gao, S. Yang, Q. Yang, Colloids and Surfaces A : Physicochemical and

Engineering Aspects Adsorption of phenols on reduced-charge montmorillonites

modified by bispyridinium dibromides : Mechanism, kinetics and thermodynamics

studies, Colloids Surfaces A Physicochem. Eng. Asp. 482,222-230 (2015).

[60] A.O.F. Gases, THE ADSORPTION OF GASES ON PLANE SURFACES OF345 (1918).

[61] M. Araissi, I. Ayed, E. Elaloui, Y. Moussaoui, Removal of barium and strontium from aqueous solution using zeolite 4A., Water Sci Technol. 73 ,16-36,(2016)

[62] Qing-Song, L., Tong, Z., Peng, W., Ji-Ping, J., Nan, L. Adsorption isotherm, kinetic and mechanism studies of some substituted phenols on activated carbon fibers. Chemical Engineering Journal, 157 348-356,(2010).

[63] Liu, Q.S., Zheng, T.,Wang, P., Jiang, J.P., Li. N. Adsorption isotherm, kinetic and mechanism studies of some substituted phenols on activated carbon fibers. Chemical Engineering Journal, 157, 348-356, (2010)

[64] Foo, K.Y., Hameed, B.H. Insights into the modeling of adsorption isotherm systems.

Chemical Engineering Journal, 156, 2-10(2010).

[65] Shen D., Fan J., Zhou W., Gao B., Yue Q., Kang, Q. Adsorption kinetics and isotherm of anionic dyes onto organo-bentonite from single and multisolute systems. Journal of

Hazardous Materials, 172 (2009) 99-107.

[66] Islam, M.T., Aimone, F., Ferri, A., Rovero, G. Use of N-methylformanilide as swelling agent for meta-aramid fibers dyeing: Kinetics and equilibrium adsorption of Basic Blue 41. Dyes and Pigments, 113,554-561, (2015).

[67] S. Dawood, T.K. Sen, Removal of anionic dye Congo red from aqueous solution by raw pine and acid-treated pine cone powder as adsorbent : Equilibrium, thermodynamic , kinetics ,mechanism and process design, Water Res. 46 (2012) 1933-1946. 
[68] Errais, E., Duplay, J., Darragi, F., M'Rabet, I., Amélie Aubert, A., Huber, F., Morvan, G. Efficient anionic dye adsorption on natural untreated clay: Kinetic study and thermodynamic parameters. Desalination, 275,74-81 (2011)

[69] Akbal, F., Sorption of phenol and 4-chlorophenol onto pumice treated with cationic surfactantJournal of Environmental Management, 74 239-244, (2005).

[70] Rauf, M.A., Bukallah, S.B., Hamour, F.A., Nasir A.S. Adsorption of dyes from aqueous solutions onto sand and their kinetic behaviour. Chemical Engineering Journal, 137,238-243 (2008)

[71] Demirak, A., Dalman, O., Tilkan, E., Dilek Yildiz, D., Yavuz, E., Gökçe, C. Biosorption of 2,4 dichlorophenol (2,4-DCP) onto Posidonia oceanica (L.) seagrass in a batch system: Equilibrium and kinetic modelling. Microchemical Journal, 99, 97-102,(2011)

[72] T.S. Anirudhan *, P.G. Radhakrishnan, Thermodynamics and kinetics of adsorption of $\mathrm{Cu}(\mathrm{II})$ from aqueous solutions onto a new cation exchanger derived from tamarind fruit shell, J. Chem. Thermodynamics 40,702-709. (2008) 